\title{
EL ORIGEN DE LAS VILLAE ROMANAS EN CATALUÑA
}

\author{
POR
}

ORIOL OLESTI VILA *

Universitat Autònoma de Barcelona

\section{RESUMEN}

En el presente artículo se realiza un estudio amplio de los núcleos rurales de época republicana en Cataluña (zonas litoral y pre-litoral), que pone en cuestión la interpretación tan ampliamente aceptada de la aparición de villae romanas desde finales del s. II a.C. Los últimos yacimientos excavados y el reestudio de algunos más antiguos permiten constatar la importancia del mundo indígena en transformación (el mundo «ibérico final») en contraposición a una presencia «colonial» escasa. A partir de esta constatación se propone un nuevo modelo de interpretación histórica.

\section{SUMMARY}

This article wants to be an in-depth study of the rural setlements of Republican age on the coast of Catalonia (Spain). It will question the currently widely accepted interpretation of the beginning of the villa system at the end of the Ind century B.C. The last sites that have been excavated together with the revision of others previously studied, allow us to verify the importance of a changing indigenous population as opposed to a scarce «colonial» presence. From these facts a new model of historical interpretation is proposed.

En la literatura arqueológica predominante es usual la referencia a la cronología especialmente precoz en que tuvo lugar la implantación de las $v i$ llae romanas en Cataluña, la puesta en práctica de lo que algunos autores han venido en llamar el «sistema de la villa». Grosso modo, este florecimiento de las villae se iniciaría a partir de la segunda mitad del s. II a.C. y se completaría a lo largo de la primera mitad del siglo i a.C., con lo que la extensión de este «sistema de la villa» se habría consumado prácticamente en época augustea ${ }^{1}$. Cataluña, especialmente su sector costero, se ha convertido así en un caso paradigmático para explicar el rápido desarrollo de las villae fuera de Italia, en un modelo que antecede incluso cronológicamente a numerosas regiones de la misma península tirrénica, y

* Este trabajo forma parte del proyecto de investigación dirigido por el Prof. A. Prieto, «Espacio social del poder en la Hispania Romana», DGICYT PB93-0868. Agradecemos al «Servei d'Arqueologia de la Generalitat de Catalunya» las facilidades dadas para la consulta de las memorias de excavación inéditas. que ha sido utilizado como un punto de referencia para interpretar otros procesos de romanización ${ }^{2}$.

También es frecuente que este surgimiento de las villae sea puesto en relación con la llegada de importantes contingentes de población itálica y romana, colonos que trajeron al Nordeste de la Península nuevas técnicas constructivas y nuevos modelos arquitectónicos y urbanísticos, reflejo de un nuevo tipo de relaciones sociales de producción. La presencia de villae republicanas no haría sino demostrar el elevado grado de romanización de estos territorios y la antigüedad del proceso.

Este modelo interpretativo, sin embargo, ha sido ya cuestionado en algunas zonas ${ }^{3}$ y parece ser en realidad menos sólido de lo esperado. Como veremos, los datos arqueológicos no parecen demostrar las cronologías tan antiguas de las villae catalanas, sino más bien todo lo contrario. Se impone en realidad una clarificación de estos datos para evitar así la tan frecuente presencia de lo que podríamos llamar «bolas de nieve» historiográficas, desmitificando algunos tópicos y presentando nuevos elementos para la reflexión histórica.

${ }^{1}$ En una breve enumeración de los investigadores que proponen esta evolución podemos citar a Prevosti, 1981 y 1991; Guitart, 1987 y 1993; Miret et alii, 1988 y 1991; Mayer-Rodà, 1986; Prevosti-Sanmartí-Santacana, 1987; Miró, 1988; Nolla, 1995, etc.

2 Como pequeña muestra de autores que han tomado el modelo «costero catalán» como ejemplo, citaremos a Richardson (1986: 173), Keay (1990), Leveau et alii (1993: 43), Ruiz-Molinos (1993: 277-279), Villanueva (1994), etc. Para todos ellos la costa catalana fue densamente poblada por villae republicanas, constatadas arqueológicamente (son recurrentes las referencias a la villae del Maresme o a ejemplos como L'Olivet d'en Pujol-Tolegassos). Esta evolución contrasta con la de otros territorios y así Le Roux (1995: 136) destaca la paradoja de que en la misma Bética la aparición de las villae es muy posterior a la de Cataluña, justificándolo sin embargo con una explicación poco convincente (las consecuencias de las Guerras Civiles en el Sur).

${ }^{3}$ En este sentido fue pionera la investigación de la Prof. Rosa Plana en el territorio del Empordá, donde se cuestionó la existencia de estas villae republicanas (Plana, 1990). Más recientemente, yo mismo he analizado esta cuestión en el Maresme (Olesti, 1995; Olesti, en prensa), y A. Aguilar (1993) en el Vallès. Una visión general en Prieto, 1995. 


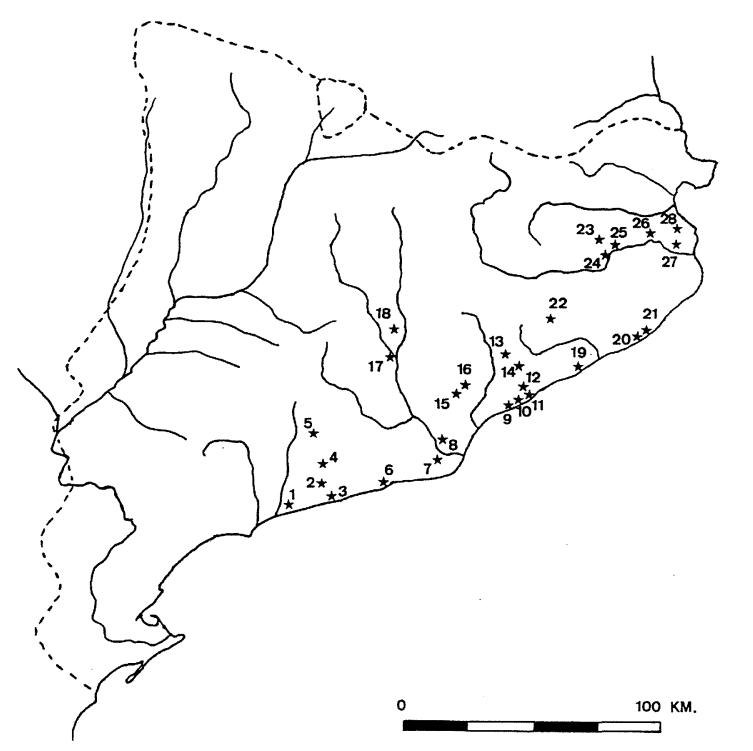
1. El Moro
2. L'Argilera
3. El Vilarenc
4. L'Albornar
5. Barranc del Prat
6. Darró
7. La Muntanyeta
8. Plaça de les Bruixes II
9. Cal Ros de les Cabres
10. Riera de Teià
11. Torre Llauder
12. Can Balençó
13. Can Martí
14. Can Rossell

15. Can Feu

16. La Salut

17. Boades

18. Can Ramón

19. El Roser

20. Mas Carbotí

21. Vil.la dels Atmetllers

22. Can Pons

23. Vilauba

24. Pla de l'Horta

25. Casa del Racó

26. Camp del Bosquet

27. Mas Gusó

28. Vil.la dels Tolegassos

Fig. 1.-Situación de los yacimientos citados en el artículo.

Seguidamente presentamos un conjunto de yacimientos significativos, que nos permitirán observar algunas características generales del poblamiento rural de época republicana. Posteriormente, a partir de estos datos, propondremos un nuevo modelo de interpretación histórica.

\section{LOS DATOS ARQUEOLÓGICOS}

No pretendemos aquí entablar una discusión sobre qué es o no es una villa ${ }^{4}$, ni tampoco nos es posible reestudiar sistemáticamente todo el conjunto de estas hipotéticas villae republicanas catalanas. Nos limitaremos a analizar, a partir de los datos ofrecidos por los propios arqueólogos que excavaron estos yacimientos, algunos ejemplos significativos de entre los más citados, pues a través de su reestudio es posible plantear una nueva interpretación. A su vez, recogeremos también los datos de algunos yacimientos arqueológicos excavados recientemente que han aportado estructuras de s. II-I a.C., pero que lejos de ser villae constituyen magníficos ejemplos de establecimientos rurales del ibé-

\footnotetext{
${ }^{4}$ La cuestión ha sido tratada ampliamente por diversos autores, a los cuales nos remitimos -en España los ya clásicos Fernández Castro, 1982; Gorges, 1979; Prevosti, 1984, o los más recientes Leveau et alii (1993:.43-61), o Nolla et alii (1995: 39-5) - En cualquier caso, para nosotros la villa debe poder distinguirse arquitectónicamente de los establecimientos indígenas, y en este sentido consideramos básica la existencia de una diferenciación entre la pars urbana y la pars rustica, elemento típicamente romano.
}

rico final, es decir, de cronología republicana pero de filiación indígena. Como intentaremos demostrar a continuación, en el período republicano no hay tanta diferencia entre unos y otros.

Lógicamente algunos problemas, como la posibilidad de atribuir filiaciones étnicas o culturales a partir del registro material, o la cuestión de las villae «rústicas», se interpondrán en nuestro discurso, pero ello no creemos que afecte a los resultados finales. Proponemos una nueva lectura de los datos arqueológicos que no pretende cuestionar los resultados conseguidos por los investigadores que trabajaron en estos yacimientos, sino tan sólo abrir nuevas vías a la interpretación histórica.

Veamos seguidamente algunos ejemplos representativos de estas supuestas villae republicanas ${ }^{5}$. Para seguir un orden de exposición claro, hemos agrupado estas villae básicamente en torno a tres subregiones catalanas, litorales y pre-litorales, tomando como referencia el actual sistema comarcal: la zona sur (Baix Penedés, Alt y Baix Camp, Tarragonés, Garraf), la zona centro (Baix Llobregat, Maresme, Vallés, Bages) y la zona norte (Empordà, Gironés, Pla de l'Estany y Selva). Se trata de tres

\footnotetext{
${ }^{5}$ No podemos entrar en detalles respecto a la cultura material de estos yacimientos, debido a la lógica falta de espacio. Deberemos así hablar de «campanienses A y B» o de «cerámica común ibérica» sin especificar, aunque somos conscientes de las limitaciones de esta información. También es necesario recordar que no han sido publicados de una manera completa los materiales de buena parte de estos yacimientos.
} 
áreas con una elevada densidad de poblamiento antiguo y una notable información arqueológica.

\section{La zona sur}

Las interesantes prospecciones llevadas a cabo por el equipo del Prof. Keay (1989:126) en el ager Tarraconensis han puesto de relieve la elevada densidad de yacimientos rurales de tradición indígena que perviven en época republicana, así como la aparición de nuevos establecimientos a partir de la segunda mitad del s. II a.C. Aunque a estos nuevos yacimientos se los consideró inicialmente villae, en realidad los materiales superficiales no permitían afirmarlo ${ }^{6}$. Más recientemente, Keay ya los califica de probables granjas ocupadas por indígenas, aunque sigue defendiendo la existencia de algunas $v i$ llae, como El Moro y L'Argilera (Keay 1990:130). Veámoslas rápidamente.

- L'Argilera (Calafell, Baix Penedés). Aunque Keay la define como una «no-sofisticada granja romana», l'Argilera es un yacimiento ibérico final que responde a las tradiciones constructivas y de cultura material ibéricas (Sanmartí et alii, 1984). Su evolución se repetirá en otras zonas: inicialmente se documenta un sector ocupado por silos ibéricos, amortizados en el s. IV a.C., donde en el último cuarto del s. II a.C. se construye un pequeño núcleo rural de carácter indígena ${ }^{7}$. El lugar se abandona a principios del s. I a.C., cuando mostraba una elevada presencia de innovaciones técnicas romanas: $t e-$ gulae, pavimentos y enlucidos obtenidos con un mortero de arena y cal, dolia, elevada presencia de piezas y ánforas itálicas, etc. A pesar de ello, el tipo de muros y de hogares y los elementos de la cultura material (con el predominio absolutơ de los materiales ibéricos, donde destaca la presencia de cerámica a mano de tradición local) permiten afirmar la filiación indígena del yacimiento.

- El Moro (Torredembarra, Tarragonés). A pesar de ser un yacimiento muy citado, sólo se conoce de él una única publicación, poco clarificadora para nuestro trabajo (Terré, 1987). La villa existe

\footnotetext{
${ }^{6}$ Keay, en su meritorio trabajo, clasifica los yacimientos superficiales que presentan materiales del s. IV-III a.C. como «ibéricos», mientras que aquellos que presentan materiales del s. II-I a.C. son llamados «romano-republicanos» (Keay, 1987: 54). Se presupone así un tipo de filiación cultural diferente según la cronología y se hace difícil identificar el poblamiento ibérico final.

7 Sanmartí et alii, 1984: 21. Es destacable también la presencia de algunos materiales residuales de s. il a.C. en las estructuras de habitación (p. 29 y 30).
}

con seguridad como tal a inicios del s. I d.C., cuando se data la construcción de unas termas que reaprovechan estructuras anteriores, sin fechar. El sector más antiguo excavado corresponde a dos habitaciones pavimentadas con signinum decorado con teselas blancas. Sus muros no presentan cal, sino arcilla, y un zócalo enlucido en negro. Se localizaron también unos depósitos y canalizaciones de función desconocida. Los materiales recuperados (desconocemos cuáles) confirman la ocupación inicial de estas estructuras entre finales del s. II a.C. e inicios del I a.C., y su perduración hasta el s. I d.C. A esta fase debe pertenecer también un capitel toscano reaprovechado en estructuras posteriores. $\mathrm{La}$ villa se abandona en época flavia ${ }^{8}$.

- EL Vilarenc (Calafell, Baix Penedés). Considerado por algunos como un ejemplo de villae republicana, los datos arqueológicos muestran tan solo la existencia de un establecimiento augusteo y altoimperial, donde han aparecido materiales fuera de contexto de finales del s. II a.C. y del I a.C. e incluso materiales ibéricos del s. IV a.C. (Palet et alii, 1993: 731). Las estructuras, que corresponden a una villa propiamente dicha (con una espléndida pars urbana asociada a un conjunto termal), son del segundo cuarto del s. I d.C. y fueron precedidas por un núcleo industrial augusteo (donde se produjeron ánforas vinícolas, entre ellas las Dressel 1 tarraconenses, Revilla, 1995). Sin embargo, en los niveles iniciales del establecimiento augusteo el porcentaje de material ibérico final respecto al romano es abrumador ${ }^{9}$. Se trata en parte de «materiales residuales», indicativos de la existencia previa de un núcleo ibé-

\footnotetext{
${ }^{8}$ Desgraciadamente no se conoce ni la estratigrafía del yacimiento ni el inventario de los materiales. Ello nos impide saber si existen también aquí materiales ibéricos finales, así como la posible existencia de sub-fases en la evolución de la fase I. En cualquier caso parece probable la existencia de unas termas augusteas y de un establecimiento lujoso más antiguo.

9 Así, en la U.E. 3022, un nivel fundacional, frente a 16 fragmentos de cerámica de paredes finas, 5 fragmentos de común itálica, y 18 fragmentos de cerámica reducida, encontramos 386 fragmentos de cerámica ibérica (donde destacan piezas como los kalathoi, bordes de cuello de cisne, etc.). Asimismo, a nivel anfórico, frente a los 15 fragmentos de ánfora itálica, 3 fragmentos de africana y 29 fragmentos de romana indeterminada, aparecen 404 fragmentos de ánfora ibérica. No se trata de un estrato atípico, es constante el material ibérico final que aparece en los niveles augusteos: fragmentos de campaniense A y B, 1 fragmento de ánfora grecoitálica, ánfora Dressel 1, ánforas apúleas y, destacando siempre en los porcentajes de materiales de estos niveles, abundante cerámica ibérica: ánfora de boca plana, kalathoi, piezas discoidales, fusayolas, e incluso cerámica a mano (en la U.E. 3007; Pou-Revilla, 1993). En las excavaciones de 1994 ha aparecido incluso un horno cerámico que correspondería a estas estructuras de la segunda mitad de s. II a.C. (Pou-Revilla, 1996: 109).
} 
rico final en el mismo emplazamiento o cerca de él, pero también este material de filiación indígena parece definir la cultura material de los pobladores de época augustea ${ }^{10}$. Como veremos, no se trata de un caso único.

Frente a estas hipotéticas villae republicanas, conocemos en esta zona sur numerosos ejemplos de yacimientos indígenas de cronología republicana, es decir, ibéricos finales. Han sido excavados recientemente, lo que ha permitido identificar claramente su filiación indígena y no confundirlos con una villa.

- Barranc del Prat (Juncosa, Baix Penedés). Se ha identificado aquí un establecimiento ibérico final, dividido en dos ámbitos, con muros de piedra seca (Burés et alii, 1993). Alrededor se han excavado cinco silos, cuatro de los cuales son contemporáneos (aparece campaniense A y B, imitaciones locales de campaniense, kalathoi, común ibérica, cerámica a mano muy abundante, etc.). En algunos silos aparecieron restos de dolia y molinos circulares. El quinto silo, sin embargo, fue amortizado con material de finales del s. III e inicios del II a.C., por lo que respondería al poblamiento del ibérico pleno. El yacimiento se abandonó a principios del s. I a.C.

- L'Albornar (Sta. Oliva, Baix Penedés). Aquí se ha localizado un pequeño hábitat ibérico final, del cual se conocen al menos cuatro ámbitos, en dos de los cuales aparecieron silos (Macias-Remolà, 1993). El material es claramente de filiación ibérica, con abundante presencia de ánfora ibérica, cerámica a mano, fusayolas, etc. El hábitat tiene un precedente del ibérico pleno, con dos silos y estructuras murarias amortizadas a finales del s. III e inicios del II a.C. El yacimiento se abandona definitivamente a mediados o segunda mitad del s. I a.C. A unos $600 \mathrm{~m}$ de este yacimiento apareció un horno cerámico rectangular, de tipo romano (aunque los muros de soporte del talud donde está construi-

${ }^{10}$ Algunos autores han puesto en relación estas estructuras del Vilarenc con la última fase de ocupación del poblado de Alorda Park, situado a $1 \mathrm{~km}$ de distancia. Allí, en la primera mitad del s. I a.C., sobre las ruinas del poblado abandonado hacia el tercer cuarto del s. II a.C, se erige una estructura que según Sanmartí-Santacana (1993: 193) recuerda lejanamente a las villae del Lacio. Sin embargo, la planta publicada no parece demasiado clara y en cualquier caso su ubicación encima del poblado, junto con la pervivencia más o menos clara de la ocupación indígena, tampoco parece demostrar la existencia de una villa republicana ex nihilo, sino más bien la continuidad en la ocupación residual indígena (una evolución similar a la detectada en otros poblados ibéricos catalanes). También podría tratarse de un caso parecido al detectado en Mas Gusó, que más adelante veremos. Además, es posible la existencia de un pequeño núcleo rural ibérico pleno en el mismo centro de «El Vilarenc», como ya indican Palet et alii (1993: 742), si tenemos en cuenta algunos materiales «residuales» aparecidos en el sector I. do son de piedra seca). No se conoce su producción, pero es significativo que en L'Albornar apareciese cerámica común deformada y quemada, que debió de producirse en las inmediaciones.

- Villa de Darró (Vilanova, Garraf). La villa propiamente dicha aparece tan sólo en los primeros años del s. II d.C., aunque el poblamiento en la zona se remonta al s. v a.C. (López, 1991; López et alii, 1992; AA.VV., 1995: 301). El lugar se encuentra inicialmente ocupado por un establecimiento ibérico pleno, que a partir de la primera mitad del s. II a.C. sufre importantes transformaciones urbanísticas, convirtiéndose en un poblado muy romanizado (nueva red de calles, con cisternas y canalizaciones, utilización de técnicas constructivas romanas, etc.). Este núcleo se abandona hacia el 50/40 a.C. y en los niveles de amortización de las estructuras, junto a un conjunto material de origen ibérico (con presencia de cerámica a mano, fusayolas, etc.), aparecen elementos como tegulae y fragmentos de signinum. Si seguimos a López (1991: 148), probablemente se trata de materiales procedentes de un nuevo establecimiento ubicado muy cerca, sin solución de continuidad, del cual conocemos el sector dedicado a la producción de ánforas vinarias que inicia su producción con las ánforas Pascual 1 y similares (las llamadas Darró 1, 2, 3). En cualquier caso, los materiales de los niveles de abandono son indicativos del origen indígena de sus ocupantes y de su elevado grado de romanización. Finalmente, este centro industrial, situado cerca de una hipotética villa augustea, no excavada, se abandona a principios del s. II d.C., coincidiendo de nuevo con la fundación a escasos metros, ahora sí, de la villa romana propiamente dicha.

Para concluir con esta zona meridional, no estaría de más recordar que algunos estudios sobre el poblamiento antiguo desarrollados en estas comarcas, como por ejemplo en el Alt y Baix Penedés (Miret-Revilla, 1990: 211; Cebrià et alii, 1993), destacan la superposición de los yacimientos republicanos a establecimientos dispersos ibéricos y la dificultad en establecer su origen indígena o romano-itálico. Tampoco hay datos para hablar de villae, y cuando hay información procedente de excavaciones ésta apunta más bien a una filiación indígena del yacimiento.

\section{La zona centro}

De nuevo aquí deberemos limitarnos a dar algunos ejemplos, pues se trata de una zona con gran cantidad de información arqueológica. Como hemos 
hecho para la zona sur, presentaremos primero los yacimientos calificados como villae republicanas, para posteriormente dar algunos ejemplos de hábitats ibéricos finales.

- Plaça de les Bruixes II (Molins de Rei, Baix Llobregat). A pesar de ser citada como un ejemplo de villa (Solias, 1993: 90), pues aparecieron en el yacimiento dos depósitos recubiertos de signinum, muros con cal y enlucidos, tegulae e imbrices, este establecimiento se define mucho mejor como un núcleo ibérico final, perduración del cercano establecimiento de la Plaça de les Bruixes I (Palau-Ribes, 1978), como lo denota la presencia entre los depósitos de un par de silos y una cultura material de filiación ibérica final, incluso con algunos grafitos ibéricos ${ }^{11}$

- La Muntanyeta (St. Boi, Baix Llobregat). Se excavaron los restos de un pequeño establecimiento del que se conocen diversos silos y restos de un depósito en signinum, del s. II-I a.C. Parece tratarse de un nuevo hábitat ibérico final, como lo hace pensar la presencia de una campaniense B con un grafito ibérico (Albareda et alii, 1986: 64).

- Torre Llauder (Mataró, Maresme). No se conocen estructuras del s. II a.C. o primera mitad del I a.C., aunque hay un importante lote de materiales de esta época que proceden del yacimiento, con elementos de filiación indígena ${ }^{12}$. Las primeras estructuras conocidas corresponden a un centro productor de ánforas, datable en torno a la segunda mitad de s. I a.C., con producción de Pascual 1 y Dr. $2 / 4$ (AA.VV., 1995: 292). Entre el año 15 a.C. y el cambio de Era, sobre estos hornos se construye un nuevo edificio, correspondiente a una esplendorosa $v i$ lla con una zona termal, aunque la decoración musivaria que conocemos deberá esperar a una remodelación de época severa. De nuevo, pues, en un lugar con precedentes dentro del ibérico final y tras una fase donde el lugar es un centro productor de

"El material recuperado comprende campaniense B, ánfora Dressel 1, ánfora ibérica, kalathoi, platos, ollas y páteras de cerámica a mano, fusayolas, fragmentos de dolium, etc. Es muy indicativa la presencia de grafitos ibéricos sobre ánfora de boca plana (Palau-Ribes, 1978: fig. 24).

12 Algunos fragmentos de campaniense A y B, cerámica ibérica pintada, gris ampuritana (una con un grafito latino y otra con un grafito «en forma de fletxa», probablemente ibérico, signo «U»), una pequeña olla de cerámica a mano, una tapadera en cerámica común romana con un grafito ibérico (Prevosti, 1981: fig. 67.7), monedas ibéricas de Iltirces, Eusti, Sedeiscen, Iaca, Neroncen, tres monedas de Ebusus del s. I a.C., y un falso denario del 74 a.C. (Prevosti, 1981: 251 ss.). Incluso en intervenciones recientes se localizó en contexto residual un fragmento del Taller de las Pequeñas Estampillas. Aunque no hay estructuras, el material parece indicar la presencia de algún tipo de establecimiento más antiguo, quizás arrasado por las estructuras posteriores. ánforas, en época augustea o poco después se instala una villa.

- Cal Ros de les Cabres (Masnou, Maresme). Es una de las villae más lujosas del Maresme. Las estructuras más conocidas, localizadas en los trabajos antiguos (termas, mosaicos, piezas escultóricas), corresponden a las fases alto-imperiales (con una gran fase en época severa, como lo demuestra el estudio de los mosaicos) ${ }^{13}$. Recientemente se excavaron las áreas industriales, localizándose diversos hornos cerámicos y sus testares (que producían ánfora Laietana 1 y Pascual 1), así como depósitos vinícolas, una prensa, almacenes de dolia, etc. (Burés-Marquès, 1991). Se identificaron niveles del s. II-I a.C., que corresponden a los restos de un depósito recubierto de signinum. El nivel más antiguo (U.E. 28) presenta un material que podemos calificar de ibérico final ${ }^{14}$. Estos materiales deben ponerse en relación con los materiales recuperados en los trabajos antiguos (Prevosti, 1981: campaniense A y B, ánfora Dressel 1, ánfora de boca plana, kalathoi, etc.), así como con los «estratos ibéricos» localizados por Serra Ráfols, que ahora sabemos debían ser posiblemente ibéricos finales. En este contexto, es de gran interés la publicación de un grafito ibérico sobre un fragmento de campaniense A (Panosa, 1993: 188) procedente de este yacimiento.

- Riera de Teià (Masnou, Maresme). Extracciones de tierra destruyeron aquí algunas habitaciones de una villa. Entre los materiales recuperados, básicamente alto-imperiales, aparecieron algunas imitaciones de barnices negros del s. III a.C. y un fragmento de greco-itálica (Prevosti, 1981: 85), así como material ibérico final: campaniense A y B, ti-

13 Prevosti, 1981: 72. La pars urbana de la villa fue «excavada» a finales del siglo pasado. Serra Ràfols (1962) continuó los trabajos en los años 40, localizando unos interesantes y polémicos «estratos ibéricos bajo villas romanas». A pesar de que autores como Keay (1990: 135) citan la existencia aquí de una granja con muros de piedra y mortero y un pavimento de signinum decorado con teselas, datado a finales del s. II-inicios del s. I a.C., esto no puede ni mucho menos afirmarse. No hay ninguna conexión estratigráfica entre estas estructuras y los hipotéticos niveles republicanos, pues fueron excavadas por Ll. Galera siguiendo un peculiar registro. Como es típico de las villae del Maresme, bien estudiadas por Prevosti (1981), de estos yacimientos conocemos tan sólo unas estructuras ya excavadas y una mínima parte de los materiales recogidos depositados en algún museo. Datar las estructuras de las villae por los materiales más antiguos no parece lo más correcto. Un estudio más global y detallado en Olesti, 1995.

14 Cerámica común ibérica, kalathoi pintados, ánfora ibérica y ánfora itálica (Burés-Marquès, 1990). Un nivel superior del depósito (U.E. 21) tiene unas características similares: cerámica ibérica, un bicónico de cerámica reducida, ánfora ibérica e itálica. Además, el signinum está compuesto por fragmentos de ánfora itálica y cerámica ibérica tardía (Olesti, 1995). 
najas ibéricas pintadas, ánfora ibérica, cerámica a mano, etc. Recientes excavaciones (Carreras et alii, 1992) han identificado la existencia de estructuras alto y bajo-imperiales. En los niveles inferiores, sin embargo, han aparecido estructuras construidas en piedra seca irregular, que utilizaba también fragmentos de tegulae y ánfora, así como la huella de un dolium. De estas estructuras sólo se conoce el estrato de amortización (por ejemplo U.E. 1012), de mediados del s. I d.C., pero entre este material hay también campaniense $\mathrm{B}$, cerámica común de tradición ibérica, ánfora Dressel 1 Laietana, ánfora Laietana 1, ánfora ibérica, Dressel 1 itálica, etc. Además, entre el material recuperado antiguamente ya había fragmentos de cerámica de tradición ibérica y ánfora Dressel 1 Laietana de mala cocción y deformados, indicio de la existencia cercana de un horno de filiación indígena productor de ánfora y cerámica.

- El Roser-Mujal (Calella, el Maresme). El lugar es ocupado desde época ibérica plena, aunque sólo se conoce un estrato sin estructuras. Posteriormente, tras un hiato del s. III a.C. o primera mitad del II a.C., el lugar se ocupa de nuevo. No conocemos tampoco estructuras, sino una buena cantidad de materiales del S. II-I a.C. presentes en niveles augusteos (campaniense A, B y B-oide, cerámica común ibérica e itálica, ánfora ibérica y Dressel 1A, cerámica a mano, etc.). Todo este hábitat sufre una importante remodelación en época de Augusto, cuando se erigen nuevas construcciones que denotan un fuerte grado de romanización (un lacus en signinum, una área con dolia, etc.). Sin embargo, como destaca López (1989: 204), estas nuevas construcciones siguen utilizando las técnicas ibéricas, con muros de piedra y arcilla (algunos con fragmentos de tegulae) y la cultura material, con cerámica a mano, sigue siendo ibérica final. A su vez, al pie de la colina se establece un horno productor de cerámica común y ánforas (Laietana 1 y después Pascual 1 y Dr. 2/4). Significativamente, la cerámica producida sigue los módelos ibéricos: kalathoi, bicónicos, etc. Incluso en alguna ánfora aparece un grafito y una estampilla que puede interpretarse como ibérica (López, 1989: 169, fig. 8). El yacimiento se abandona prematuramente (aparece en los últimos niveles T.S. Sud-gálica).

- Can Martí (Samalús, Vallès Oriental). Esta posible villa se encuentra situada en la vertiente de un pequeño cerro, en lo más alto del cual se encuentra situado un establecimiento ibérico (Puig Castellar). Al pie del cerro se conservan también los restos de un horno cerámico antiguo sin datar. La villa de Can Martí fue «vaciada» por aficionados en los años 50 y reestudiada por Aquilué-Pardo (1990), que tan sólo pudieron contar con el material abandonado en el lugar. De la villa apenas se conoce una superficie de $10 \times 7.50 \mathrm{~m}$, aunque se ha reproducido a partir de cuatro ámbitos incompletos la planta general ${ }^{15}$. Los elementos más destacables del yacimiento son dos pavimentos en opus signinum (decorados con teselas que dibujan formas geométricas) y uno en opus tessellatum sin decoración (aunque probablemente existió un emblema central), así como los restos de estuco pintado hallados en el ámbito 3 . El material recuperado en el yacimiento marca un periodo de ocupación breve, finales del s. II a.C./1 ${ }^{\mathrm{a}}$ mitad del s. I a.C., si bien existen paralelos que podrían llegar a mediados del s. I a.C. Entre el material destaca de nuevo el elevado porcentaje de material ibérico, como la cerámica gris de la costa catalana, la cerámica pintada, ánforas, etc. Destacamos por ejemplo la presencia de tres piezas discoidales en cerámica oxidada ibérica ${ }^{16}$

- Can Rossell (Llinars, Vallès Oriental). En una zona bien conocida por la existencia de restos romanos alto-imperiales, se excavó un sector con niveles del s. II-I a.C. (Sánchez-Barrassetes, 1989). Se trata de un edificio estructurado en torno a un patio central, identificado como un almacén y no como un hábitat, que se abre a una amplia calle a través de una gran puerta. Frente a este edificio, al otro lado de la calle, se encuentran los restos de otro edificio, no excavado. Todas las habitaciones estaban pavimentadas con tierra batida, excepto una que presentaba signinum. El tipo de muros (de tapial o adobe, sólo de arcilla, sin cal), de tradición local, contrasta de nuevo con la presencia de elementos de tipo romano, como la utilización de tégula, el enlucido de cal en algunas paredes, la existencia de una cloaca en el patio con un sofisticado sistema de fil-

15 Planta restituida que responde al modelo itálico de villa de planta axial, con atrio y tablino (si bien algún muro aparece ligeramente desviado). Los paralelos de este tipo de planta se encuentran, como señalan X. Aquilué y J. Pardo, en Ampurias, Badalona, Cartagena o Celsa. Sin embargo, su restitución coincide también exactamente con la planta de la «casa de Likine» en la ciudad indígena de Caminreal (Vicente, 1991).

${ }_{16}$ Aunque son evidentes las influencias foráneas en este yacimiento, algunos elementos, como el tipo de muros, calificados como de opus incertum por los autores, se corresponden bastante bien con el tipo de muro de tradición ibérica, llamado de piedra seca (si bien se utiliza frecuentemente la arcilla como mortero). También es significativo que los mejores paralelos para la decoración musivaria o pictórica que citan los autores se encuentren en núcleos indígenas romanizados como Azaila, Botorrita, Glanum o Lattes (AquiluéPardo, 1990: 96). Algunos ejemplos recientes refuerzan esta filiación local: los signina decorados de Salduie, Andelos o Caminreal, o las pinturas de estilo pompeyano de Azaila, Botorrita o Caminreal (Asensio, 1995: 392-94). 
tro en plomo, una área de almacenaje en dolia, abundante presencia de ánforas vinarias itálicas, elementos metálicos, etc. Entre el material recuperado, que puede datarse entre mediados del s. II a.C. y mediados del I a.C. ${ }^{17}$, destaca la presencia de campaniense A y B, ánfora Dressel 1 y 2/4, ánfora púnica, cerámica común itálica e ibérica, kalathoi, ánfora ibérica, moneda ibérica, etc. También es significativa la presencia de cerámica ibérica a mano (U.E. 30, 41), así como la existencia de diversas piezas de cerámica campaniense $\mathrm{B}$ con grafitos ibéricos (U.E. 25; Panosa, 1991), lo que parece delimitar un horizonte ibérico final. En cualquier caso, no estaríamos tampoco frente a una villa, sino a una zona de almacenes estructurados en torno a una calle o vía central, con una clara funcionalidad de redistribución y tal vez de producción.

- Can Feu (St. Quirze, Vallés Occidental). La ocupación del lugar se inicia con un conjunto de 25 silos del ibérico pleno y, tras un hiato de primera mitad del s. II a.C., continúa con un asentamiento del ibérico final, tal y como lo definen Carbonell et alii (1991: 151). Se ha excavado un conjunto alineado de unos 20 silos y fosas ibéricas, amortizados con material como la campaniense A y B, ánfora itálica, cerámica a mano, ibérica pintada, fragmentos de pavimento de arcilla cocida, adobe, dolia, tegulae, etc. Poco antes del cambio de Era, sobre este núcleo productivo, y quizás tras un breve hiato de algunas décadas, se sitúa un centro de producción agrícola e industrial: un edificio de planta rectangular, un pozo, diversos silos para almacenar grano, un almacén de dolia, un depósito de decantación de arcilla y un horno cerámico (que produjo Pascual 1 y Dr. $2 / 4$, con alguna estampilla ibérica ${ }^{18}$ ). A mediados del s. I d.C. se remodela el edificio, con un nuevo lacus, un mayor almacén de dolia y tres nuevos hornos. El centro se abandona a finales del s. II d.C. Se ha calificado el yacimiento como villa, a pesar que no hay ningún resto de una posible pars urbana. En cualquier caso, no existe como villa en época republicana e incluso en época augustea sigue siendo un centro productivo (con silos) y no residencial.

- La Salut (Sabadell, Vallés Occidental). El lugar fue excavado en los años 40 , identificándose una importante villa y un centro productor tanto de án-

\footnotetext{
17 En los niveles de amortización de las estructuras aparece ya campaniense B-oide. Es interesante destacar que de forma residual ha aparecido también un fragmento de una pieza Morel 2764a, que podría datarse a finales del s. III a.C., quizás indicio de una ocupación anterior.

${ }^{18}$ Entre las marcas anfóricas de los envases producidos en Can Feu, aparecen algunas claramente ibéricas (Martínez et alii, 1987: fig. 4.11, signo «ko», y posiblemente 4.3, 4.10).
}

fora como de cerámica. Parece clara la existencia de unos niveles previos ibéricos finales (con campaniense A y B, Dressel 1). También se detectaron materiales típicos del ibérico pleno, indicio de una ocupación anterior (López Pérez, 1994). La primera estructura bien datada que se conoce es un horno de planta rectangular, que contenía en su interior ánforas Laietana 1. No obstante, se ha documentado una producción anterior de Dressel 1 Laietanas, una de ellas con la marca M.COS. También algunas ánforas presentan grafitos, alguno ibérico (Casas, 1987: Fig. 9.10). La producción anfórica parece terminar con las Laietanas 1 o poco después y a mediados de s. I d.C. se inicia la producción de T.S. Hispánica.

- Boades (Castellgalí, Bages). La villa romana de Boades se encuentra situada en la confluencia de los ríos Llobregat y Cardener, en un punto de gran interés estratégico, ya ocupado desde el s. vi a.C. (Daura et alii, 1995). Un gran asentamiento del ibérico pleno, con una zona dedicada al almacenamiento de grano en silos, fue el precedente de un establecimiento ibérico final localizado también en los trabajos arqueológicos. Se identificó un conjunto de silos del S. II-I a.C., así como un estrato con material ibérico de este periodo (donde apareció cerámica a mano), un pavimento y un hogar, ubicado inmediatamente por debajo de los niveles de la estructura alto-imperial. Entre los materiales aparecidos en el silo $\mathrm{n}^{\circ} 1$ destacan la campaniense A y B, la cerámica ibérica a mano, ánfora ibérica, gris ampuritana, kalathoi pintados y diversas piezas con grafitos ibéricos, así como uno en latín, vinum. Sobre estas estructuras se construye, dentro de la segunda mitad del s. I a.C., sin solución de continuidad, un edificio de función productiva, identificado como la pars rustica de una villa (aunque la villa propiamente dicha podría ser posterior). También se han excavado dos hornos cerámicos, sin que se conozcan sus producciones.

Contrastando con estos yacimientos (calificados como villae por determinada bibliografía), han sido excavados recientemente algunos establecimientos que de nuevo deben ser calificados como ibéricos finales, de filiación indígena, y que no presentan problemas de interpretación. Veremos tan sólo dos ejemplos.

- Can Balençó (Argentona, Maresme). Es un hábitat ibérico final, con diversos ámbitos domésticos (cada uno con su hogar, de tipología ibérica, correspondientes a diversas familias), donde se han incorporado ya las técnicas romanas (Codex, 1992). Los muros son de piedra y arcilla, si bien se utilizan también fragmentos de tegulae. Los pavimentos son de tierra batida y la cobertura de tegulae. No 
hay silos, por lo que no se trata de una granja, sino de un área de hábitat, quizás relacionada con la existencia cercana de áreas de producción cerámica y anfórica (Can Notxa, etc.). La cultura material es claramente indígena: cerámica ibérica mayoritaria, con presencia de cerámica a mano, piezas discoidales, etc. El núcleo se funda en la segunda mitad del s. II a.C. (aunque hay materiales del ibérico pleno residuales) y se abandona en época de Augusto.

- Can Ramón (Santpedor, Bages). En época ibérica plena el lugar es ocupado por un pequeño asentamiento rural, con diversas habitaciones y algunos silos, que se abandona a finales del s. III a.C. (Cura-Sánchez, 1992). Durante la segunda mitad del s. II a.C. el lugar es ocupado de nuevo por un conjunto de tres habitaciones estructuradas en torno a un muro común, separadas por un hipotético patio de una cuarta habitación. En el área intermedia se construyó una estructura absidal, que podría corresponder a un estanque. La planta de las estructuras es bastante irregular y sus muros responden de nuevo a la tipología ibérica ${ }^{19}$. Al lado de las construcciones se excavaron un mínimo de dos silos con material del s. II-I a.C. El yacimiento parece abandonarse definitivamente dentro de la primera mitad del s. I a.C. (no hay B-oides). Entre el material aparecido destaca la campaniense A y B, ánfora Dressel 1A, ánfora PE 16, cerámica común itálica y africana, y material ibérico: ánfora de boca plana (19\% del total de los fragmentos recuperados), cerámica a mano, fusayolas, etc. Es significativa la presencia de un grafito ibérico en una pieza campaniense.

Así pues, como hemos visto, en toda esta zona centro la evolución cronológica parece ser similar y numerosos yacimientos parecen seguir unas mismas pautas. Lógicamente, tan sólo hemos podido reflejar aquí una parte de los datos conocidos, pero en algunos territorios más estudiados, como el Maresme (Olesti, 1995) o el Baix Llobregat, se han documentado otros muchos ejemplos (Vila Vella de St. Boi, Castell de Castelldefels). Para el caso del Vallés, las excavaciones recientes de algunos yacimientos (l'Aiguacuit, Can Jofresa, etc.) muestran también cómo la edificación de las villae es posterior a Augusto, y normalmente se produce en un segundo momento en la evolución del establecimiento, hacia finales del s. I d.C. En cualquier caso, no parecen yacimientos tan alejados de los ya vistos, pues por ejemplo en Can Jofresa han sido recu-

19 A pesar de que los autores sugieren que pueda tratarse de la pars rustica de una posible villa republicana, parece claro que estamos frente a un nuevo núcleo de filiación indígena, como lo demuestra la continuidad de ocupación, la presencia de silos y la cultura material. peradas algunas piezas con grafitos ibéricos (Panosa, 1991: yac. $n^{\circ} 21$ ).

\section{La zona norte}

Nos referimos aquí a las comarcas más occidentales de la provincia de Gerona, bien conocidas a nivel arqueológico y que presentan numerosos yacimientos con niveles republicanos. De nuevo seleccionaremos algunos casos paradigmáticos, presentando primero algunos ejemplos de hipotéticas villae republicanas para después recoger algunos ejemplos de hábitats ibéricos finales.

- Villa dels Atmetllers (Tossa, la Selva). En el lugar donde se alza la villa hubo desde mucho antes un poblado ibérico, según lo califica A. López (AA.VV., 1995: 287). Más que de un poblado parece tratarse de un establecimiento menor, del cual se conocen algunas estructuras del período ibérico final (II-I a.C): diversos silos y los restos de una habitación, de clara filiación ibérica (López, 1992: 81). De todas maneras hay materiales dispersos del ibérico pleno. El estrato de amortización de las estructuras ibéricas finales se corresponde con la misma capa arqueológica que se utilizó para elevar este sector al construirse las estructuras de la pars urbana de la villa propiamente dicha, en los años finales del s. I a.C. ${ }^{20}$. Este edificio augusteo es mal conocido, pero podría tratarse de una villa de corredor. Dentro de la primera mitad del s. II d.C. el edificio sufre fuertes remodelaciones, con la construcción de un pórtico y unas termas, tomando un aspecto mucho más suntuario.

- Mas Carbotí (Tossa, la Selva). A finales del s. I a.C. se edificó en este punto un centro vinícola, del que se conocen una serie de estancias alineadas a ambos lados de un pasillo central (López et alii, 1987: 324). Los muros son de piedra y arcilla, calificados como de técnica ibérica, si bien en el aparejo también se incluyen fragmentos de tegulae (López et alii, 1985). Sin embargo, en estos estratos aparecen numerosos fragmentos de campaniense B, algunos de A, y ánfora Dressel 1B, indicios de una ocupación anterior. El centro parece estar ligado a una actividad productiva y se abandonará en época flavia, por lo que no parece lo más adecuado calificarlo de villa. Del lugar se conocen producciones de ánfora (Pascual 1 y Dr 2/4) y de cerámica común, que presentan formas inspiradas en precedentes ibéricos.

${ }^{20}$ Hay por lo tanto una clara continuidad entre las dos fases, como ya destaca A. López, partidario de hablar de una reconversión de la población indígena del lugar (1992: 81). 
- Vilauba (Camós, Pla de l'Estany). La villa propiamente dicha se construye hacia finales del s. I d.C. y de ella conocemos su parte urbana (donde destaca la identificación de un larario), así como algunos ámbitos dedicados a actividades productivas (como la producción de aceite). Del período republicano sólo se conocen materiales aparecidos en fosas y rellenos hallados en el terraplenamiento previo a la construcción de la villa (sobre todo ánforas ibéricas e itálicas), datables a finales del s. II- inicios del I a.C. A pesar de los pocos datos, los autores creen en la existencia de una villa de época republicana (AA.VV., 1995: 277).

- Casa del Racó (St. Julià de Ramis, Gironés). A principios del s. I a.C., en la vertiente septentrional del monte donde se encuentra ubicado el poblado ibérico de St. Julià se edificó un pequeño establecimiento agrícola, del que se conocen tres muros que delimitan una estancia, en cuyo interior apareció un silo. Los arqueólogos reconocen que, si bien las estructuras no son típicamente romanas, tampoco son típicamente ibéricas. Parece claro que estamos frente a otro pequeño hábitat ibérico final. A finales del s. I o principios del s. II d.C. sobre este hábitat se edificó un gran edificio de planta cuadrangular, estructurado en torno a un patio subdividido en dos sectores, que podría corresponder a la verdadera villa. Para ello fue necesario realizar un gran aterrazamiento, donde se han encontrado materiales provenientes de la fase anterior (Agustí et alii, 1993: 26).

- Villa dels Tolegassos (Viladamat, Alt Empordà). Hacia mediados del s. I d.C. se construyó una gran villa en este punto, sobre los restos de estructuras anteriores. Así, de la segunda mitad avanzada del s. II a.C. datan los estratos de relleno de un depósito y dos silos, donde aparecieron «restos de hogares y techumbres de un modesto edificio típicamente ibérico, mezclados, en uno de los estratos, con fragmentos de pavimento de opus signinum decorado con teselas de color blanco» (AA.VV., 1995: 278) ${ }^{21}$. La sub-fase posterior correspondía a dos depósitos para líquiidos en signinum y varios silos de tipo indígena excavados en el subsuelo, todo ello amprtizado con escombros donde aparecieron materiales de finales de época de Augusto. Entre estos materiales aparecieron elementos constructivos,

21 A sólo $600 \mathrm{~m}$ del yacimiento se conoce la existencia de otro centro ibérico final, l'Olivet d'en Pujol. A la primera ocupación corresponden tres silos del s. IV a.C. Tras un hiato, a finales del s. II a.C. se construye encima un almacén de 75 dolia. Los muros del almacén y de una cabaña asociada eran de piedra seca y el pavimento de tierra batida. El establecimiento se abandona en época de Augusto y la cultura material es de filiación ibérica final (Casas, 1989). como restos de mosaico cuatricolor, fragmentos de columnas de caliza y restos de pintura mural. Para algunos serían los restos de una hipotética villa de tipo itálico, destruida. También de época augustea data la construcción de un edificio de gruesos muros de piedra sin argamasa, relacionado con dos pozos, sobre el cual se construyó en época de Claudio la villa definitiva.

- Pla de l'Horta (Sarrià de Dalt, Gironès). Esta villa, excavada de manera parcial en los años 70 para evitar su destrucción, presenta unos suntuosos niveles alto-imperiales (Nolla, 1982-83). Sin embargo, es muy poco lo que se conoce de los niveles inferiores (sólo tenemos los diarios de excavación), alcanzados únicamente en dos sondeos. A partir de estas actuaciones puede establecerse una interesante pero poco contrastada secuencia. El lugar era ya frecuentado en época ibérica plena (bajo un pavimento de signinum se hallaron cuatro incineraciones en urnas de orejetas, al lado de las cuales apareció una espada de hierro). Además, en diversos puntos del yacimiento apareció, en estratos posteriores, material del ibérico pleno, un posible indicio de continuidad. De la hipotética villa republicana sólo se conoce un sólido muro de piedra y argamasa aparecido en el sondeo de la habitación A, que podría estar relacionado con el estrato IV, donde apareció abundante campaniense $\mathrm{B}$, cerámica gris ampuritana, cerámica de engalba blanca, kalathoi pintado y ánforas Dressel 1. También en la habitación B, en un estrato alto-imperial, apareció material de este momento: cerámica reducida muy poco depurada, posiblemente hecha a torno lento y de tradición local, bicónicos ampuritanos, ibérica pintada y ánfora tarraconesa (con una marca incisa antes de la cocción, «CY», que podría corresponder a los signos ibéricos «ke-ü»). En cualquier caso, de un solo tramo de muro no podemos inferir el aspecto global del establecimiento. En la segunda mitad del s. I d.C. se edifica la mayor parte del centro, que será reformado y embellecido a inicios del s. III d.C.

- Mas Gusó (Bellcaire, Alt Empordà). La villa está ubicada en un cerro ya ocupado por un establecimiento ibérico del s. VI al II a.C. La estación indígena ocupaba todo este pequeño cerro, pues en todas las catas aparecen niveles ibéricos bajo los romanos, aunque sólo se ha identificado un muro del periodo prerromano. A finales del s. II a.C. (y sobre estratos donde aparece material ibérico pleno así como cerámica a mano o ánforas Dresel 1) se construye un nuevo edificio, sostenido por un gran muro con contrafuertes, elemento de clara filiación itálica. Otros elementos arquitectónicos documentan estas influencias foráneas, si bien subsisten también 
algunos muros de piedra seca, sin cal (Casas, 1996: 169). A juzgar por los materiales, no parece haber ningún hiato entre los niveles ibéricos finales y los de la «villa». Este segundo edificio tiene continuidad y sufre diferentes reformas en época alto-imperial. A finales del s. II d.C. se construyen unas termas en el sector oeste, bajo las cuales de nuevo apareció un estrato con materiales del s. II a.C.

Frente a estos yacimientos con niveles republicanos-ibéricos finales que han podido en algún caso ser interpretados como villae, se conocen algunos ejemplos de yacimientos considerados unánimemente como indígenas.

- Camp del Bosquet (Camallera, Alt Empordà). Se trata de un yacimiento identificado sin lugar a dudas como indígena, ibérico final ${ }^{22}$. Está constituido por un pequeño ámbito, con un basamento de pequeñas piedras, arcilla y cal y con una cobertura vegetal que también utiliza tegulae e imbrices. A su lado se encuentra un silo, así como un depósito-aljibe en opus signinum posiblemente relacionado con la producción de vino o aceite. El yacimiento se abandona en época de Augusto, pero los materiales apuntan a una cronología inicial de segunda mitad del s. II a.C. (campaniense A, Lamb. 55, Dressel 1A, imitación local de campaniense, etc.). Es significativa la presencia de cerámica a mano, dolia y diversos fragmentos de molino.

- Can Pons (Arbúcies, La Selva). El yacimiento está formado por tres sectores. En el primero se excavó un conjunto de seis habitaciones organizadas de una forma regular, que ha sido definido por sus excavadores como una «masía ibérica» cuya cronología va de mediados del s. II a la primera mitad del s. I a.C. Entre la cerámica predominan las producciones a mano de clara tradición local, frente a una reducida presencia de importaciones (campaniense A y B, ánfora itálica y púnica) y un notable conjunto de cerámica ibérica a torno (grises de la costa catalana, ánfora, kalathoi, etc.). También es significativa la presencia de fusayolas y dolia, así como la ausencia de tégulas. A unos $100 \mathrm{~m}$, en el sector 2, se excavó un almacén de dolia, donde la presencia de cerámica ibérica a mano era también muy importante y donde ya había tegulae. El sector 3 es tardorromano, aunque en superficie se han hallado materiales altoimperiales. En resumen, parece tratarse de un nuevo establecimiento ibérico final, dedicado a

${ }^{22}$ Nolla et alii (1995: 35) contraponen precisamente este yacimiento y algún otro como Serra de Daró (que no recogemos por falta de espacio), a las fincas de origen itálico, que consideran muy diferentes. El caso de Camp del Bosquet sería un claro ejemplo de hábitat indígena. la producción vinícola (se hallaron restos de vitis vinifera y de almendras tanto en el sector 1 como 2 ), con una cronología antigua y en un contexto claramente indígena ${ }^{23}$.

No queremos extendernos más en este inventario de yacimientos, aunque debemos recordar que otros muchos establecimientos de esta zona norte parecen seguir una evolución similar (como el caso de Llafranc), especialmente por lo que hace referencia a la cronología inicial de los edificios que podemos considerar claramente como villas, casi siempre bien entrado el s. I d.C. (por ejemplo Puig Rodon, Font del Vilar, y otros).

\section{UNA PRIMERA LECTURA DE LOS DATOS ARQUEOLÓGICOS}

Tras este limitado repaso a los datos arqueológicos (plasmado en el cuadro sinóptico, fig. 2) es conveniente destacar algunos aspectos que parecen repetirse en gran número de yacimientos y que plantean una problemática de gran interés.

Una primera cuestión a tratar es la de la cronología inicial de estos yacimientos y la presencia en estos niveles de materiales «residuales» más antiguos. Como hemos visto, la mayor parte de villae y yacimientos analizados son bastante bien conocidos para las fases alto y bajo imperiales, pero es poco lo que sabemos de los niveles republicanos. En realidad, la mayor parte de las veces se reduce a materiales residuales en estratos más tardíos y a alguna estructura aislada. Ello nos plantea el problema de la valoración de este tipo de materiales en contextos posteriores y hasta qué punto son indicio de una presencia más antigua. Creemos que la cuestión sería muy difícil de establecer si se plantease en un único yacimiento, donde siempre cabría la posibilidad de que se hubieran producido movimientos de tierras, azarosos procesos post-deposicionales, etc., pero parece bastante claro que la cuestión afecta a la mayoría de estos núcleos, por lo que debemos intentar dar una explicación global. Consideramos que la presencia tan abundante de materiales más antiguos (y tan homogéneos) debe ponerse en rela-

${ }^{23}$ Font et alii (1994). Can Pons es el primer hábitat sedentario localizado en el curso alto y medio de la Riera de Arbúcies, zona muy poco poblada hasta época medieval. Se trata de un área que podríamos considerar marginal y ello puede explicar algunas características de la cultura material de Can Pons (predominio de la cerámica a mano de tradición pre-ibérica, no utilización de tegulae en la zona de hábitat). Ello hace todavía más interesante la identificación aquí de un establecimiento ligado a la producción de vino, con sistemas de almacenaje de origen romano. 


\begin{tabular}{|c|c|c|c|c|c|c|c|c|c|c|}
\hline & $\begin{array}{l}\text { Preceden- } \\
\text { tes ibérico } \\
\text { pleno }\end{array}$ & $\begin{array}{l}\text { Silos II-I } \\
\text { a.C. }\end{array}$ & $\begin{array}{c}\text { Estructu- } \\
\text { ras piedra } \\
\text { seca }\end{array}$ & $\begin{array}{c}\text { Cerámica } \\
\text { a mano }\end{array}$ & $\begin{array}{l}\text { Cerámica } \\
\text { ibérica } \\
\text { a torno }\end{array}$ & $\begin{array}{l}\text { Grafitos } \\
\text { ibéricos }\end{array}$ & $\begin{array}{l}\text { Pavimen- } \\
\text { tos } \\
\text { signina }\end{array}$ & $\begin{array}{c}\text { Elementos } \\
\text { lujosos } \\
\text { itálicos }\end{array}$ & $\begin{array}{c}\text { Hornos } \\
\text { anfóricos }\end{array}$ & $\begin{array}{l}\text { Dolia y } \\
\text { tegulae }\end{array}$ \\
\hline L'Argilera & $\mathrm{X}$ & & $\mathrm{X}$ & $\mathrm{X}$ & $\mathrm{X}$ & & & & & $\mathrm{X}$ \\
\hline El Moro & & & $\mathrm{X}$ & & & & $\mathrm{X}$ & $\mathrm{X}$ & & $\mathrm{X}$ \\
\hline El Vilarenc & $\mathrm{X}$ & & & $\mathrm{X}$ & $\mathrm{X}$ & & & & $\mathrm{X}$ & $\mathrm{X}$ \\
\hline Barranc Prat & $X$ & $X$ & $\mathrm{X}$ & $X$ & $X$ & & & & & $\mathrm{X}$ \\
\hline L'Albornar & $\mathrm{X}$ & $\mathrm{X}$ & $\mathrm{X}$ & $\mathrm{X}$ & $\mathrm{X}$ & & & & $X ?$ & \\
\hline Darró & $\mathrm{X}$ & & $\mathrm{X}$ & & $\mathrm{X}$ & & $\mathrm{X}$ & & $X$ & $\mathrm{X}$ \\
\hline Plaça Bruix. & $x$ & $X$ & & $X$ & $\mathrm{X}$ & $X$ & $X$ & & & $X$ \\
\hline Muntanyeta & & $\mathrm{X}$ & & & $\mathrm{X}$ & $\mathrm{X}$ & $\mathrm{X}$ & & & $\mathrm{X}$ \\
\hline Tor. Llauder & $\mathrm{X}$ ? & & $\mathrm{X}$ & $\mathrm{X}$ & $\mathrm{X}$ & $\mathrm{X}$ & & & $\mathrm{X}$ & $\mathrm{X}$ \\
\hline Cal Ros C. & & & & & $X$ & $X$ & $X$ & & $X$ & $X$ \\
\hline Riera Teià & $\mathrm{X}$ ? & & $X$ & $\mathrm{X}$ & $\mathrm{X}$ & & & & $\mathrm{X}$ & $\mathrm{X}$ \\
\hline El Roser & $\mathrm{X}$ & & $\mathrm{X}$ & $\mathrm{X}$ & $\mathrm{X}$ & $\mathrm{X}$ & $\mathrm{X}$ & & $X$ & $\mathrm{X}$ \\
\hline Can Martí & $x$ & & $\mathrm{X}$ & & $\mathrm{X}$ & & $\mathrm{X}$ & $X$ & $\mathrm{X}$ ? & $\mathrm{X}$ \\
\hline Can Feu & $\mathrm{X}$ & $\mathrm{X}$ & & $\mathrm{X}$ & $\mathrm{X}$ & estampilla & & & $\mathrm{X}$ & $\mathrm{X}$ \\
\hline La Salut & $\mathrm{X}$ & & & & $\mathrm{X}$ & $\mathrm{X}$ & & & $X$ & \\
\hline Can Rossell & $\mathrm{X}$ ? & & $\mathrm{X}$ & $\mathrm{X}$ & $\mathrm{X}$ & $\mathrm{X}$ & $\mathrm{X}$ & filtro plomo & & $x$ \\
\hline Boades & $\mathrm{X}$ & $\mathrm{X}$ & & $\mathrm{X}$ & $\mathrm{X}$ & $\mathrm{X}$ & & & $\mathrm{X}$ ? & $\mathrm{X}$ \\
\hline C. Balençó & $\mathrm{X}$ & & $\mathrm{X}$ & $\mathrm{X}$ & $\mathrm{X}$ & & & & $X ?$ & $\mathrm{X}$ \\
\hline Can Ramon & $\mathrm{X}$ & $X$ & $\mathrm{X}$ & $\mathrm{X}$ & $\mathrm{X}$ & $\mathrm{X}$ & & & & $x$ \\
\hline Ametllers & $\mathrm{X}$ & $X$ & & & $\mathrm{X}$ & $\mathrm{X}$ & & & & \\
\hline M. Carbotí & & & $\mathrm{X}$ & & $X$ & & & & $\mathrm{X}$ & $\mathrm{X}$ \\
\hline Vilauba & & & & & $\mathrm{X}$ & & & & & \\
\hline Casa Racó & $\mathrm{X}$ & $\mathrm{X}$ & & & $\mathrm{X}$ & & & & & \\
\hline Tolegassos & $\mathrm{X}$ & $\mathrm{X}$ & $\mathrm{X}$ & & $X$ & & $X$ & $\mathrm{X}$ & & $\mathrm{X}$ \\
\hline Pla Horta & $\mathrm{X}$ & & & & $\mathrm{X}$ & $\mathrm{X}$ ? & & & & \\
\hline Mas Gusó & $\mathrm{X}$ & & $\mathrm{X}$ & $\mathrm{X}$ & $\mathrm{X}$ & & $\mathrm{X}$ & & & $\mathrm{X}$ \\
\hline C. Bosquet & & $X$ & & $X$ & $\mathrm{X}$ & & $\mathrm{X}$ & & & $X$ \\
\hline Can Pons & & & $\mathrm{X}$ & $\mathrm{X}$ & $\mathrm{X}$ & & & & & $\mathrm{X}$ \\
\hline
\end{tabular}

Fig. 2.-Elementos documentados en los niveles de cronología republicana de los yacimientos analizados (materiales publicados), por orden de aparición en el texto.

ción con la existencia efectiva de estructuras anteriores, construcciones que frecuentemente fueron arrasadas por la edificación de las villae o establecimientos alto-imperiales y que difícilmente (salvo excepciones) han llegado hasta nosotros. Ello no implica, sin embargo, que los núcleos anteriores fuesen también villae, sino que, como se ha visto, podía tratarse de núcleos ibéricos finales. En otros casos no sabemos cuáles fueron estas estructuras más antiguas, lo que es una razón más para no calificarlas como villae.

En segundo lugar, y como puede observarse en la fig. 2, es también bastante clara la existencia en gran parte de los yacimientos (bien sean las supuestas villae o los hábitats del ibérico final) de precedentes del mundo ibérico pleno ${ }^{24}$. Es cierto que en

${ }^{24}$ De los 28 yacimientos, 21 presentan indicios del periodo ibérico pleno. Catorce de ellos están situados o bien enci- algunos casos hay un hiato en la ocupación (sobre todo durante la primera mitad del s. II a.C.), pero ello no impide que haya una clara relación, aunque tan sólo sea de superposición, entre estos yacimientos de cronología republicana y los antiguos establecimientos del ibérico pleno.

En tercer lugar, deberíamos detenernos en la cuestión de la cultura material que aparece en estos niveles republicanos. Personalmente, hemos optado por calificar de «ibérico final», y como tal de filiación indígena, a un conjunto de materiales en los que, como se ha visto, aparece campaniense A y B, ánfora Dressel 1 y cerámica común itálica, pero

ma de estructuras (por ejemplo silos), o bien a muy corta distancia (en la pendiente de una colina ocupada por un hábitat ibérico, etc.). En otros seis casos esta relación no es tan clara, pero han aparecido materiales residuales del ibérico pleno. Finalmente, en un caso existe un establecimiento ibérico muy cercano (Olivet d'en Pujol-Tolegassos). 
donde predomina básicamente el material ibérico: cerámica común, kalathoi, ánforas de boca plana, cerámica gris ampuritana o de la costa catalana, fusayolas, piezas discoidales, etc. Es frecuente en estos contextos hallar cerámica a mano, así como grafitos ibéricos, lo que creemos define un horizonte cultural de cariz plenamente local, una muestra de la presencia de población indígena. El hallazgo en sólo un yacimiento de este conjunto de materiales podría no ser significativo, pero es muy reveladora su presencia en la mayoría de ellos ${ }^{25}$.

Un cuarto aspecto a destacar es la cuestión de las estructuras arquitectónicas de época republicana. Donde ha sido posible establecer una datación arqueológica (y por lo tanto con elementos en estratigrafía) nos encontramos frente a sencillas habitaciones con muros de piedra seca y arcilla (con claros paralelos en el mundo local), que utilizan a veces en el paramento fragmentos de tegulae y imbrices y que aparecen frecuentemente asociadas a silos (una estructura de almacenaje agrícola típicamente indígena). También presentan innovaciones adquiridas a través del contacto con Roma: techumbres de tegula, almacenes de dolia, depósitos en signinum, algunos muros con cal, etc. ${ }^{26}$. En realidad se trata del mismo tipo de técnicas constructivas que pueden detectarse en este mismo periodo en algunos oppi$d a$ indígenas fuertemente romanizados, como $\mathrm{Bu}-$ rriac (con un espectacular almacén de dolia que puede responder a una metrología romana, Olesti, 1995: 100), Torre Roja, Darró, St. Julià de Ramis, o el mismo núcleo ibérico de Tarraco (Prieto, 1995). No debemos confundir, como tantas veces ha sucedido, las estructuras posteriores, augusteas o altoimperiales, con las estructuras modestas más antiguas.

Tan sólo en cuatro casos (El Moro, Can Martí, Mas Gusó y, con algunas dudas, en Els Tolegassos) estamos frente a elementos constructivos y decorativos que parecen indicar la presencia de edificios lujosos, con evidentes influencias itálicas, y que denotan la presencia de personajes probablemente

\footnotetext{
${ }^{25}$ Como puede observarse en el cuadro sinóptico, lotes significativos de material ibérico a torno aparecen en 27 de los 28 yacimientos estudiados. Cerámica a mano y/o grafitos ibéricos en 20 de los 28 yacimientos. Desconocemos si puede haber elementos similares en otros yacimientos, donde la totalidad del material no ha sido publicado. A su vez, fragmentos de tegulae y/o dolia aparecen en 21 de los 28 casos. Se trata de un conjunto de materiales bastante homogéneo.

${ }_{26}$ De un total de 28 yacimientos analizados, 11 presentan silos del s. II-I a.C., 16 estructuras con muros de piedra seca y 11 pavimentos de signina. No se trata de hacer estadística con estos datos, sino tan sólo mostrar cómo elementos de filiación ibérica y romana se encuentran entremezclados en este conjunto de yacimientos, sin excluirse mutuamente.
}

aristocráticos (pavimentos de signina con teselas, pintura mural, etc.). Sin embargo, tanto el contexto y los precedentes ibéricos de tres de los cuatro yacimientos (Mas Gusó, Tolegassos y Can Martí), como la existencia de paralelos en otras regiones (como veremos más adelante), nos plantean abiertamente la cuestión del origen de sus ocupantes, que no forzosamente debe ser extrapeninsular. En esta misma línea, es también muy interesante el yacimiento de Can Rossell, que ofreciendo un planteamiento arquitectónico innovador (patio central, amplia puerta de entrada, pavimento de signinum, desagüe central con filtro) corresponde a una zona de almacenes ocupada por una población del ibérico final, indígena, como lo atestigua la cultura material y los grafitos ibéricos ${ }^{27}$.

Un quinto elemento a destacar (también reflejado en la fig. 2) es la aparición de hornos de producción anfórica y cerámica en buena parte de estos yacimientos (o en su inmediata proximidad) a partir de mediados del s. I a.C. Es posible identificar una evolución en tres fases (hábitat ibérico final / horno / villa augustea o altoimperial) que se repite en distintos yacimientos ${ }^{28}$. Parece claro que en la mayoría de los lugares la etapa de los hornos anfóricos precede a la villa propiamente dicha, pudiendo existir paralelamente a los hornos zonas de producción o almacenaje, que en ningún caso pueden ser definidas como villae.

Finalmente, a todo lo dicho anteriormente es importante añadir que la cronología inicial de las villae propiamente dichas parece situarse, en algunos casos, en época augustea (Torre Llauder, Tolegassos, villa dels Atmetllers, quizás las termas de El Moro, Boades) o ya entrado el periodo alto imperial (El Vilarenc, Darró, probablemente Cal Ros de les Cabres, Riera de Teià, Can Feu, Vilauba, Casa del Racó, Pla de l'Horta). En realidad, el s. I d.C. es el momento inicial de la mayor parte de las estructuras de villae romanas estudiadas en Cataluña (l'Aigacuit, Can Jofresa, Puig Rodon, Font del Vilar, Vila Vella de St. Boi, etc.), si bien los programas decorativos más ambiciosos acostumbran a ser posteriores, del s. II d.C. o época severa. Como ve-

27 Un paralelo bastante cercano de este yacimiento, que no hemos recogido por falta de espacio, sería el «Camp de les Lloses» (Tona, Osona), de clara filiación indígena, pero con importante presencia de elementos arquitectónicos y de cultura material romana (Molas et alii, 1995).

${ }_{28}$ Así sucede en El Vilarenc, Darró, Torre Llauder, Cal Ros de les Cabres, Riera de Teià, El Roser, Can Feu, La Salut y muy probablemente Boades. Hay indicios para suponer una evolución similar en Mas Carbotí, L'Albornar, Can Martí y Can Balençó-Can Notxa, aunque en estos casos se vio truncada antes de alcanzar la última etapa (¿quizás por un desplazamiento cercano?). 
mos, la realidad arqueológica de la villa es un fenómeno mucho más tardío de lo que se venía considerando.

\section{UN MODELO DE INTERPRETACIÓN HISTÓRICA}

Una vez presentados los datos conocidos sobre el tipo de poblamiento disperso de época republicana/ibérica final, es preciso plantear un modelo interpretativo que integre la diversidad y complejidad de elementos mostrada por la arqueología. Como hemos intentado demostrar, el modelo tradicional, que proponía la llegada de colonos itálicos establecidos en nuevas villae como pieza clave para explicar el gran desarrollo del poblamiento de finales del s. II inicios del s. I a.C., tiene escaso respaldo en los datos arqueológicos. Son muy pocos los casos de edificaciones con esta cronología que respondan a un modelo itálico, y aun menos los que, incorporando algunos de estos elementos, presenten una cultura material diferenciable de la indígena de la época. El caso más frecuente es justamente el contrario, el hábitat indígena que adopta algunas técnicas romanas, tanto constructivas (tegulae, signina) como productivas (dolia, laci, etc).

Tampoco parece prudente, a pesar de esta constatación, negar totalmente la posibilidad de que existiesen villae de colonos itálicos en época republicana, porque estos colonos efectivamente existieron, si bien en un número muy inferior al que se creía y muy inferior a lo que hubiera sido necesario para ser, realmente, el motor de estos cambios. Quizás ejemplos de estas villae pudieron ser El Moro, Can Martí, o el más hipotético caso de Mas Gusó, pero debemos reconocer que se trata de casos mal conocidos, y que, sobre todo los dos últimos, presentan elementos similares a otros hábitats ibéricos finales (pervivencia de ocupación desde el ibérico pleno, cultura material, etc.). Además, es posible calificar estos yacimientos como villae republicanas, si se quiere utilizar esta terminología (a mi modo de ver poco operativa ${ }^{29}$ ), pero no por ello estas supuestas villae hubieron de ser ocupadas por colonos itálicos, pues en el caso de los oppida se ha demostrado cómo la incorporación de patrones arquitectónicos y urbanísticos itálicos en las ciudades indígenas es una realidad en el Nordeste de la Península en época republicana ${ }^{30}$. Incluso si aceptáse-

${ }^{29}$ Ver infra nota 39.

${ }^{30}$ Bien estudiado en el Valle del Ebro (Asensio, 1995). Incluso en los casos de Caminreal, Andelos o Salduie, las élites indígenas adoptan un tipo de mansión (de planta simi- mos-que fueron villae ocupadas por colonos itálicos, representarían un porcentaje muy minoritario respecto al hábitat ibérico final, lo que de nuevo nos lleva a la necesidad de proponer otro modelo explicativo, lejos de las «oleadas» inmigratorias de finales del s. II a.C. ${ }^{31}$

Evidentemente, sería también posible el argumento hasta cierto punto contrario: ¿cómo podemos calificar una cultura material de indígena, si no hallamos tampoco la que corresponde a los colonos, mercatores o militares romanos que residían en la Península? ¿Cómo podemos diferenciarlos a partir de la cultura material? ¿Quizás algunos hábitats que consideramos ibéricos finales podrían ser los establecimientos modestos de estos colonos, las llamadas villas rústicas? Aunque ello no pueda descartarse completamente, la presencia en la mayor parte de estos centros de cerámica a mano y grafitos ibéricos, así como la evidente continuidad mostrada en muchos casos respecto a establecimientos del ibérico pleno, permiten pensar que la mayor parte pertenecen a la población local. Pero si incluso estos elementos arqueológicos, para nosotros tan significativos, no fueran suficientes, la misma similitud en la cultura material entre los dos grupos poblacionales ya sería por sí mismo un hecho histórico relevante ${ }^{32}$.

lar a la restituida para Can Martí), directamente inspirada en las mansiones de la aristocracia romana, lo que demuestra que estamos frente a unos grupos en proceso de asimilación, de integración tanto política como cultural. Elementos similares pueden encontrarse en poblados ibéricos catalanes como Burriac, Darró, Olérdola, o la reciente edificación descubierta en Alorda Park, donde se utiliza el signinum, se siguen esquemas urbanísticos itálicos, se construye en opus quadratum, etc. En realidad, para el caso concreto de los signina, es posible considerar (como hace Asensio, 1995: 394) que se trata de un elemento más relacionado con las élites indígenas que con verdaderos personajes itálicos (aunque éstos fueron sus introductores, lógicamente). En esta línea podría interpretarse también la mansión de la «Plaça Gran» en Iluro, muy similar (Olesti, 1995: 105).

31 En esta línea, Keay (1996: 161) descarta el asentamiento masivo de itálicos en esta zona (si bien posteriormente se contradice en parte (Keay, 1996: 173) al considerar como un factor fundamental para la romanización el asentamiento masivo de ciudadanos romanos también en el área catalana). Creemos, en cualquier caso, que este reciente modelo de Keay es sugerente y muy interesante, aunque, como veremos, discrepamos con él en algunos aspectos.

${ }^{32}$ Si pudiera confundirse la cultura material de los colonos con la de la población local, ello sería el reflejo de un tipo de sociedad donde esta diferencia no sería fundamental, una sociedad donde los colonos gozarían del mismo nivel económico que los indígenas y donde frente a la diferencia de origen prevalecería la diferencia en las relaciones sociales de producción, lo que de nuevo nos llevaría a un modelo diferente al del «sistema de la villa», que considera al poblamiento local como marginal, transitorio (Miret et alii, 1987 y 1991). Respecto a la villa rústica, nos parece un término confuso y en cierto modo contradictorio, poco operativo. 
A partir de todas estas reflexiones, creemos que es posible plantear un nuevo modelo de interpretación, más complejo pero también más sugerente. Para ello debemos remontarnos inicialmente a la época ibérica plena.

Como ha quedado constatado por los yacimientos que hemos estudiado, existe ya en época ibérica plena un importante poblamiento disperso en Cataluña, centros rurales dedicados a la producción agrícola y al almacenamiento en silos. Casi todos ellos sufren un importante colapso hacia finales del s. III a.C.-inicios del s. II a.C., que queda reflejado especialmente en la amortización de silos y de estructuras de habitación (fenómeno que también se ha constatado a nivel de oppida). A pesar de ello, un número importante de estos pequeños establecimientos tendrá continuidad en época ibérica final.

A lo largo de la primera mitad del s. II a.C. constatamos un considerable vacío de información en muchos yacimientos, lo que puede hacerse extensivo de nuevo a numerosos oppida. Se trata de un hiato bastante generalizado que responde a un doble motivo: por una parte a las transformaciones que sufren las pautas territoriales indígenas, afectadas por la intervención romana, y por otra parte a un problema estrictamente arqueológico: la dificultad de identificar claramente estos niveles a partir de los materiales de importación. Este hiato no se ha constatado sólo en los yacimientos catalanes, sino que se refleja también en otras zonas ${ }^{33}$. Es evidente que el mundo ibérico catalán está sufriendo los primeros cambios impuestos o inducidos por Roma y esto se refleja a nivel de pautas de ocupación del territorio ${ }^{34}$.

Todos los investigadores están de acuerdo en considerar el periodo de la segunda mitad del s. II a.C.-inicios del s. I a.C. como el momento en el que se intensifican estas transformaciones, el periodo de más intensa romanización. El fenómeno es percep-

${ }^{33}$ Como por ejemplo en Lattara, en el sur de Francia, puerto de llegada de ánforas ibéricas de la costa catalana donde en la primera mitad del s. II a.C. éstas prácticamente desaparecen, para recuperar su presencia en la segunda mitad del siglo (Py, 1990: 344-345). Para la problemática de los materiales, ver Olesti, 1995: 125 ss.

${ }^{34}$ Discrepamos aquí de la interpretación de Keay (1996: 161), que observa una gran continuidad en el poblamiento ibérico de la zona catalana hasta el s. I a.C. Hay, a mediados del s. II a.C, un fenómeno amplio de ruptura en las pautas de poblamiento en muchas áreas, especialmente a nivel de $o p$ pida secundarios (Castellruf, Turó Gros de Céllecs, Turó de Vent, poco después Castellet de Banyoles, etc.; Olesti, 1995 : 307 ss.), pero también a nivel de establecimientos rurales. Cabe pensar en una intervención más agresiva por parte de Roma y sus oligarquías, un colapso del patrón de asentamiento ibérico más antiguo y más forzado de lo que propone Keay (1996: 164). tible en buena parte de los yacimientos que hemos recopilado (se edifican ahora nuevas estructuras, se incorporan técnicas romanas, aumentan las importaciones itálicas), pero no podemos olvidar los precedentes. Muchos de estos yacimientos suponen una nueva fase de ocupación en lugares ya habitados anteriormente que respondían a unas pautas de ocupación y explotación del territorio evidentemente ibéricas y que si ahora se reocupan es porque siguen siendo útiles y productivos ${ }^{35}$. Al mismo tiempo, es ahora cuando surge un gran número de establecimientos fundados ex nihilo, nuevos hábitats que constituyen un claro indicio del fuerte cambio que se está produciendo en las pautas de poblamiento. Para nosotros, se trata de hábitats ocupados por población indígena, establecimientos surgidos a partir de un proceso de reasentamiento de la población local inducida o impuesta por Roma ${ }^{36}$ que coincide en buena parte con los fenómenos de abandono o de cambios internos en numerosos poblados ibéricos catalanes. La filiación indígena de estos nuevos asentamientos creemos que ha sido demostrada en buena parte de ellos y, como hemos visto, salvo alguna excepción, difícilmente pueden ser calificados como villae. Además, la presencia de silos en muchos de ellos nos indica que al menos durante algún tiempo siguieron dedicados a la producción agrícola que ya realizaban en época ibérica plena (probablemente cereales). Son núcleos modestos, como lo eran los de época ibérica plena, y tanto los de nueva fundación como los que perviven parecen responder más a un aumento de las zonas trabajadas y explotadas que no a una verdadera transformación de los procesos productivos (que no se producirá hasta entrada la primera mitad del s. I a.C.). Han incorporado técnicas romanas y deben desenvolverse en un nuevo marco de relaciones sociales de producción. Se ha roto con el antiguo sistema de concentración de excedente en grandes áreas de silos, bajo la protección de los oppida y ahora cada pequeño núcleo se encarga del almacenaje de una producción más modesta, que podríamos calificar de

${ }^{35}$ Podría argumentarse que se ocupan los mejores lugares, que los nuevos colonos se asientan en los lugares óptimos, como hicieron antes los iberos. Sin embargo, el fenómeno es tan amplio que, a nuestro modo de ver, sólo puede explicarse por tratarse en realidad de reocupaciones o pervivencias, y no de fundaciones ex nihilo. Además, en muchos casos tampoco se trata de lugares especialmente estratégicos o favorables, que pudieran justificar una ocupación por parte de poblaciones diversas. Es más lógico pensar en una continuidad en la ocupación, pese al hiato de unos 50 años.

${ }^{36}$ El fenómeno ha sido constatado en el Maresme (Olesti, 1995), Vallés (Aguilar, 1993) y Ampurdán (Plana, 1990), pero puede hacerse extensivo a otros territorios (Prieto, 1995). 
privatizada. Se ha roto con el modelo ibérico y se está instaurando uno nuevo, híbrido ${ }^{37}$.

Estos cambios se acentuarán durante la primera mitad del s. I a.C. En la mayor parte de los yacimientos se amortizarán los silos (con conjuntos de materiales donde aparece abundante campaniense B $\mathrm{y}$, significativamente, una notable presencia de $d o$ lia, molinos de mano, etc.) y aparecerán nuevas estructuras: almacenes de dolia y depósitos en signinum. No es difícil poner este fenómeno en relación con el origen de la producción de vino en Cataluña (será en el segundo cuarto del s. I a.C. cuando aparecen los primeros envases anfóricos vinícolas; Olesti, en prensa).

El fenómeno es de un gran interés, porque todo nos conduce a pensar que estas primeras producciones vinícolas se realizan en el marco no de las villae, que siguen sin existir, sino en el marco de estos establecimientos ibéricos finales, de filiación indígena, que se transforman para adaptarse a un nuevo tipo de producción. Esto se constata también en lo que respecta a la producción anfórica, pues las primeras ánforas vinícolas producidas, imitaciones de Dressel 1 y de Lamboglia 2, se realizan con la técnica cerámica ibérica (pastas tipo «sandwich»; Comas et alii, 1987) y en hornos que ya habían funcionado en época ibérica plena (el mejor ejemplo conocido es Sta. Cecília, en Mataró; Ribas, 198384). Otros elementos refuerzan esta interpretación, como la producción en estos hornos anfóricos no sólo de imitaciones de ánforas vinícolas itálicas (y las posteriores formas Laietana/Tarraconense 1, y Pascual 1), sino también de piezas de cerámica común que significativamente reproducen las formas típicamente ibéricas: kalathos, jarras, páteras de imitación, etc. Además, empiezan a identificarse algunas estampillas ibéricas en estas primeras producciones, así como estampillas con nomina itálicos también de gran interés ${ }^{38}$.

37 Para el territorio del Maresme, hemos considerado que este fenómeno es el reflejo en los datos arqueológicos de la instauración de un nuevo catastro, documentado no sólo por los cambios en el poblamiento (el reasentamiento) sino también por el incremento de la economía monetaria, la ruptura de las áreas comunes de almacenaje en silos, la nueva dimensión y tipología de los hábitats rurales, la diversa evolución de los oppida indígenas e incluso la posible existencia de una limitatio efectiva del área (Olesti, 1995). Para las zonas del Ampurdán y Vallés se ha constatado morfológicamente la existencia de centuriationes de esta cronología.

${ }^{38}$ En el caso de las estampillas ibéricas localizadas no puede haber duda sobre la filiación de los productores de las ánforas (o de su contenido). Recientemente, Keay (1996: 164) ha presentado una nueva sobre Dressel 1B local. Para el caso de las latinas, es significativa la presencia en las primeras estampillas de nomina relacionables con personajes con redes clientelares en la Citerior (Dyson, 1980-81), como M.
Frente a estos hábitats ibéricos finales modestos y dedicados a tareas productivas, aparecerán otros que actúan posiblemente como centros intermediarios (Can Rossell, Camp de les Lloses, etc.) y finalmente un pequeño grupo de hábitats lujosos residenciales, ocupados por las élites del momento, indígenas e itálicos (como El Moro, Can Martí o Mas Gusó ${ }^{39}$. Así pues, el verdadero fenómeno histórico es la aparición de pequeños establecimientos indígenas que ocupan intensivamente el territorio poniendo en explotación nuevas áreas agrícolas que se desvinculan claramente del antiguo modelo de los oppida. Es un reasentamiento de poblaciones que progresivamente abandonan los oppida para instalarse en nuevos lugares, rurales o urbanos.

Tampoco existe una dualidad, como algunos autores pretenden, entre un mundo marginal, ibérico final, y un nuevo mundo romano que se va imponiendo ${ }^{40}$. A nuestro parecer no hay un «ensayo» del sistema de la villa (como afirma García-Pujol, 1994), hay sólo un único mundo, el surgido tras la intervención romana, donde itálicos y élites locales colaboran perfectamente integrados en una nueva realidad híbrida (una nueva élite que se irá conformando a lo largo del s. I a.C.) y donde la población

PORCI, Q. FABI, M. COS (Cornelius?), etc., indicio de posibles personajes indígenas integrados en esta producción (el tema ha sido analizado con más profundidad en Olesti, 1996-97).

${ }_{39}$ Para nosotros no se trataría de verdaderas villae, protagonistas de un hipotético «sistema de la villa», sino de lujosas residencias rurales ocupadas por grupos privilegiados (indígenas o itálicos que probablemente residen mayoritariamente en las ciudades, tanto oppida como urbes de nueva fundación). Serían escasas las mansiones que ocupan el nivel más alto de un poblamiento rural jerarquizado específico del periodo ibérico final y que no son las protagonistas del gran incremento del poblamiento en este periodo. Llamarlas villae induce a la confusión con el modelo económico, social y político propio de un momento posterior, aunque éste sea su embrión.

${ }_{40}$ Así lo entienden, por ejemplo Miret et alii, 1988; García-Zamora, 1993; Palet et alii, 1993: 742, que consideran los hábitats ibéricos finales como la pervivencia de un mundo ibérico en decadencia o extinción (y que algunos pretenden comparar incluso con el sistema de plantación, donde es necesaria la producción local residual para mantener el sistema durante algún tiempo, antes que las nuevas explotaciones coloniales fructifiquen). No se trata de un mundo ibérico final residual, sino de centros que evolucionarán ellos mismos hacia las nuevas producciones, protagonizando el gran cambio del s. I a.C. También en este sentido disentimos del modelo de Keay (1996: 164), que propone un colapso del patrón de asentamiento nativo, que se irá marginalizando (con la excepción de algunos terratenientes ibéricos, como los que producen imitaciones de Dressel 1) y debilitándose sus redes de intercambio, frente al nuevo modelo romano, el protagonizado por el cultivo de la viña, que será el de los «terratenientes romanos» (Keay, 1996: 172). No creemos que exista esta dualidad, sino un único sistema, nuevo, impuesto por Roma en colaboración con las élites indígenas desde mediados del s. II a.C. 
local deberá adaptarse a la nueva situación social y económica. Estas nuevas pautas se concretarán, entre otras cosas, en el incremento de la monetarización, el auge del cultivo especulativo de la vid, el aumento de la producción para el mercado, etc. De este modo, será esta población indígena la verdadera protagonista del proceso de cambio y no una minoría de colonos que sólo intervendrán a un nivel marginal. No llegarán nuevos personajes que transformarán el mundo ibérico final, marginando a los indígenas y creando ex nihilo un nuevo sistema, sino que el nuevo mundo que nos aparece con claridad a partir de época augustea es el resultado de la evolución local de las poblaciones reasentadas desde la segunda mitad del s. II a.C. La causa de los cambios, lógicamente, es la voluntad de la oligarquía romana de transformar y explotar estos territorios, pero los protagonistas, los que identifica la arqueología, son los campesinos del ibérico final en profunda transformación.

Finalmente, también los acontecimientos posteriores pueden ayudarnos a comprender este fenómeno, complejo y difícil de explicar con brevedad.

Como se ha visto, hacia mediados del s. I a.C. un buen número de estos hábitats ibéricos finales se abandonan (entre los que hemos visto l'Albornar, Plaça de les Bruixes II, Can Rossell, Can Ramón, Can Pons). Para algunos autores es la prueba de la existencia de esta dualidad: al mismo ritmo que se consolidarían las villae, desaparecerían los establecimientos marginales indígenas ${ }^{41}$. Sin embargo, esta interpretación tiene un problema: seguimos sin documentar villae romanas. En realidad, a partir de mediados del s. I a.C. lo que aparecerán por doquier son centros de producción vinícola, almacenes de dolia y sobre todo hornos anfóricos. Además, estas innovaciones aparecen en los mismos centros de tradición ibérica final que habían protagonizado el reasentamiento (El Roser, la Salut, Cal Ros de les Cabres, Can Feu, etc. ${ }^{42}$. Parece claro que hay una dualidad, pero muy diferente a la que se creía: algunos centros ibéricos finales continúan en su transformación hacia las formas productivas tipicamente romanas (y aparecerán ahora centros verdaderamente industriales), mientras que otros se irán abandonando. ¿Por qué esta evolución diferenciada? Seguramente perdurarán los centros bien adaptados al

41 Ver por ejemplo Sanmartí-Santacana, 1992: 269.

${ }^{42}$ A pesar del interés por relacionar la aparición de las producciones anfóricas vinícolas con el surgimiento de las villae (Revilla, 1995: 137), los hornos anfóricos preceden en los yacimientos que hemos analizado a la propia villa: el horno no es una parte de la villa, sino en muchos casos su precedente. nuevo tipo de producción agrícola imperante (vino y aceite), con buena comunicación (se produce para un nuevo mercado) y por lo tanto rentables en el nuevo modelo social y productivo impuesto por Roma. Por contra, se abandonarán los centros menos adaptables a estos cambios ${ }^{43}$. No deja de ser significativo que se abandonen especialmente aquellos yacimientos que en la etapa anterior se mostraron más especializados en la producción o almacenaje de cereal, los grandes conjuntos de silos ${ }^{44}$.

No se trata simplemente de un grupo «más competitivo» que otro, ni de un mundo romano en avance frente al local en retroceso. En este contexto, y hablando de un imperialismo agresivo como el romano, estos conceptos podrían ser anacrónicos o cuestionables. Se trata de un nuevo tipo de ocupación y explotación del territorio que ha forzado a la población indígena a entrar en unas nuevas pautas y relaciones de producción, donde las élites (locales y romanas) han impuesto unas nuevas formas productivas y sociales y donde no hay lugar para las estructuras que no puedan integrarse en esta nueva realidad.

A corto plazo esto afectará a los oppida y hábitats indígenas, pero no sólo a ellos. Can Martí, el mejor ejemplo de casa lujosa rural republicana, o villa para algunos, se abandona también en este momento. ¿Por qué uno de los tres únicos casos que conocemos de mansión de planta itálica desaparece? Si hubiera sido una villa, ¿por qué no evolucionó como los otros yacimientos? Probablemente porque Can Martí responde más al mundo anterior, el que todavía miraba más hacia el ibérico pleno (no olvidemos su situación al pie de un poblado) que no al nuevo, simbolizado por los hornos y las producciones vinícolas. Es uno de los hábitats que parece no poder integrarse en la nueva realidad (y probablemente sus ocupantes deben haberse desplazado a un lugar cercano, más apto, o desaparecieron inmersos

${ }^{43}$ Sin perjuicio de que en muchos casos el abandono sea en realidad tan sólo el desplazamiento de las mismas poblaciones hacia un centro muy cercano, a tan sólo algunas decenas o centenares de metros, con lo que seguramente deberíamos matizar este «final masivo» del hábitat indígena frecuentemente planteado.

44 Puntualmente tampoco es descartable que algunos yacimientos de cronología republicana puedan haberse abandonado a causa de los conflictivos sucesos que tuvieron lugar en el territorio catalán a lo largo de la primera mitad del s. I a.C.: guerra sertoriana y guerra civil. Hay indicios de destrucción e incendios en diversos yacimientos, aunque ello no implica siempre el fin de la ocupación (pero sí puede suponer remodelaciones arquitectónicas, como sería el caso de Can Balençó). Es probable que no sólo los acontecimientos bélicos, sino sobre todo los juegos de alianzas con las élites indígenas, puedan explicar el diverso éxito o fracaso de algunos núcleos. 
en conflictos del momento). Los yacimientos que se abandonan muestran los profundos cambios que se están produciendo en la estructura productiva, seguramente debido a la irrupción de capital y cultivos especulativos y al auge de la producción para el mercado, pero no son sustituidos aún por las villae romanas, que deberán esperar al periodo augusteo.

Llegamos así a la época de Augusto. Será ahora cuando empezarán a aparecer verdaderas villae. La evolución exitosa de algunos de estos centros productores agrícolas (o de sus propietarios) acabará dando lugar a una nueva realidad histórica, la villa, no sólo una novedad arquitectónica, sino sobre todo un símbolo de la aparición de nuevas formas sociales y jurídicas, una nueva oligarquía provincial. El caso paradigmático es Torre Llauder: se construye la villa encima de unos hornos productores de ánforas. Otros casos serían Cal Ros de les Cabres, El Vilarenc, etc. Sin embargo, tampoco ahora todos los yacimientos superarán esta fase: El Roser nunca llegará a ser una villa. Paralelamente, en época augustea se documentan muchos abandonos de yacimientos ibéricos finales (Can Balençó, etc.). Tampoco en ello debemos ver el final de lo indígena marginal frente al triunfo de lo romano. Probablemente la introducción progresiva, ahora sí, del sistema de la villa comportará de nuevo profundas transformaciones en la estructura productiva de estos territorios, lo que podemos poner en relación con las transformaciones sociales y jurídicas que se documentan en las civitates catalanas.

No deja de ser significativo que desaparezcan algunos establecimientos rurales al mismo tiempo que se fundan otros nuevos, lo que posiblemente nos habla de procesos de concentración de tierra, de cambios en la dimensión de muchos fundi, todo ello relacionable con el surgimiento de estas villae. Cabría así interpretar el surgimiento de la villa como el final del proceso de formación de las oligarquías locales y su definitiva integración, económica, social y jurídica, en las redes clientelares de la sociedad romana.

\section{CONCLUSIÓN}

Si recopilamos la información, podemos ver cómo realmente el origen de las villae romanas en Cataluña es un fenómeno tardío, al igual que en otras zonas del Mediterráneo occidental, y que lo que se había calificado como villae republicanas corresponde a otro fenómeno histórico diferente. En época republicana (segunda mitad s. II-primera mitad s. I a.C.) no se establece ningún «sistema de la villa», sino que el mundo local se ve obligado a reasentarse e integrarse en las nuevas formas productivas y sociales impuestas por Roma, unas nuevas relaciones sociales de producción. Aquí el papel de Roma es fundamental, pues es su presión y sus intereses, con la colaboración de las élites locales, la que fuerza estos cambios. En este contexto, el papel de los colonos itálicos, escasos, no es decisivo. El proceso está dirigido por las élites locales en colaboración con la oligarquía romana, élites que residen en mansiones, a veces rurales pero preferentemente urbanas, y que incorporan las modas y técnicas romanas. La mayor parte de la población, sin embargo, lo hace en modestos establecimientos de tradición local.

La evolución posterior de estos territorios y la reorientación hacia unas formas económicas donde toma aún mayor importancia la producción para el cambio, el mercado (con la monetarización, la mejora de las vías de comunicación, el incremento de la fiscalidad, etc.), comporta una rápida y espectacular adaptación forzada de las poblaciones locales a la nueva realidad política, económica y social. En esta fase es probable una intervención más intensiva de personajes itálicos o romanos potenciando las dinámica transformadora, pero no como colonos sino como inversores, mercatores y negotiatiores que aprovechan la situación privilegiada de la costa citerior para desarrollar sus negocios ligados a la producción y exportación del vino o aceite. Como punto final a todo ello aparece la villa, pero ello no hubiera sido posible sin la existencia de una fase anterior, donde el incremento de la producción para el mercado y la exportación de productos jugó sin duda un papel fundamental.

\section{BIBLIOGRAFÍA}

AA.VV., 1995: J. Tremoleda, J. Casas, P. Castanyer, J. M. Nolla, A. López, M. Prevosti, E. Carbonell, J. Folch, J. Martínez, J. Fierro, Recent work on villas around Ampurias, Gerona, Iluro, and Barcelona (NE Spain), JRA, VIII, 271307.

Aguilar, 1993: A. Aguilar, Avanç preliminar a l'estudi dels cadastres romans a la comarca del Vallès, Estudios de la Antigüedad, 6/7, 119-132.

AĞustí et alii, 1993: B. Agustí, J. Burch, J. MeriNO,'Tombes, sitges $i$ muralles, Girona.

Albareda et alii, 1986: M. J. Albareda, M. Alonso, A. Biosca, N. Molist, F. Puig, J. Puig, R .Melian, A. Saorín, Resultats de les excavacions arqueològiques portades a terme dins del Pla 
de l'Atur a St. Boi, Tribuna d'Arqueologia 1984 1985, 63-72.

Aquilué-Pardo, 1990: X. Aquilué, J. Pardo, La vil.la romana de Can Martí (Samalús), Cypsela, VIII, 87-100.

Asensio, 1995: J. A. Asensio, La ciudad en el mundo prerromano en Aragón, Monografía Caesaraugusta 70 , Zaragoza.

Burés-Marquès, 1990: L. Burés, A. Marques, Cal Ros de les Cabres, Memòria d'excavacions 1990, Memoria Inédita, Servei d'Arqueologia de la Generalitat, Barcelona.

Burés-Marquès, 1991: L. Burés, A. Marquès, La vil.la romana de Cal Ros de les Cabres. Notícia de les darreres campanyes d'excavació, Laietania, 6, 115-118.

Burés et alii, 1993: L. BurÉs, J. Ma MACIAS, E. RAMON, El jaciment ibèric del barranc del Prat ( $\mathrm{La}$ Juncosa de Montmell), Miscel.lània Penedesenca, XVI, 114-136.

Carreras et alii, 1992: N. Carreras, L. Burès, A. Marqués, J. Estrella, Tió, Memòria de les excavacions arqueològiques d'urgència al jaciment de la Riera de Teià, Memoria inédita, Servei d'Arqueologia.

Carbonell et alii, 1991: E. Carbonell, J. Folch, J. MartíneZ, Notícia de les excavacions al jaciment ibèric i romà de Can Feu (St. Quirze del Vallès), Limes, 1, 151-154.

CASAS, 1987: T. CASAS, Estudi preliminar : les àmfores de la vil.la de la Salut (Sabadell), Arraona, 1, 15-25.

CASAS, 1989: J. CASAS, L'Olivet d'en Pujol i els Tolegassos, C.I.A.G., Sèrie Monogràfica 10, Girona.

Casas, 1996: J. Casas, Mas Gusó o Puig Moragues (Bellcaire d'Empordá). Campanyes de 1995 i 1996, III Jornades d'Arqueologia de les comarques de Girona, Sta. Coloma de Farners, 166172.

Cebrià et alii, 1991: A. Cebrià, G. Ribé, M. R. SeNABRE, L'arqueologia a l'Alt Penedès: estat de la qüestió als anys 90, Miscel.lània Penedesenca, $\mathrm{XV}, 37-135$.

CODEX, 1992: Cooperativa D'Excavacions S.C.C.L., Memòria dels treballs de delimitació de les àrees d'interés arqueològic afectades per la construcció de la variant de Mataró, Laietania, 7, 155-189.

Comas et alii, 1987: M. Comas, A. Martín, D. MATAMOROS, J. Miró, Un tipus d'àmfora Dressel 1 de producció Laietana, Jornades Internacionals d'Arqueologia Romana, Granollers, 372-378.

Cura-Sánchez, 1992: M. Cura, E. SÁnchez, Excavació al jaciment iberoromà de Can Ramón
(Santpedor), La recerca arqueològica al Bages en els darrers anys., Manresa, 123-145.

Daura et alii, 1995: A. Daura, J. Galobart, J. PIÑERO, L'Arqueologia al Bages, Manresa.

Dyson, 1980-81: S. L. Dyson, The distribution of Roman republican family names in the Iberian Peninsula, Ancient Society, 11/12, 257-299.

Fernández Castro, 1982: M. C. Fernández, Villas romanas en España, Madrid.

Font et alii, 1994: G. Font, J. Mateu, S. Pujades, J. M. Rueda, J. Tura, Can Pons (Arbúcies). Una nova aportació al coneixement del poblament antic del Montseny, Quaderns de la Selva, 7 , 131-150.

García-Pujol, 1994: J. García, J. Pujol, El poblament ibèric dispers al Maresme central: l'exemple de Can Bada, Laietania, 9, 87-130.

García-Zamora, 1993: J. García, D. Zamora, La vall de Cabrera de Mar. Un model d'ocupació de la Laietània ibèrica, Laietania, 8, 145-180.

Gorges, 1979: J. G. Gorges, Les villas Hispano-romaines, Burdeos.

Guitart, 1987: J. Guitart, La Laietània: el context històrico-Arqueològic com a marc interpretatiu de la producció i comerç del vi a la regió, $E l$ ví a l'Antiguitat. Economia, producció $i$ comerç al Mediterrani Occidental, Badalona,145-152.

Guitart, 1993: J. GuITART, Un programa de fundacions urbanes a la Hispania Citerior de principis de s. I a.C., XIV Congrès Int. Arqueologia Clàssica, (Tarragona 1993), Tarragona, 205-214.

KeAY, 1987: S. J. KeAY, The impact of foundation of Tarraco upon the indigenous settlement pattern of the ager Tarraconensis, Jornades Int. d'Arqueologia Romana, Granollers, 53-58.

Keay, 1990: S. J. KeAY, Processes in the Development of the Coastal Communities of Hispania Citerior in the Republican Period, en BLAGG-MILLET, The early Roman Empire in the West, Oxford, 120-150.

KeAY, 1996: S.J. KeAY, La romanización en el Sur y Levante hasta la época de Augusto, en J. $\mathbf{M}^{\mathrm{a}}$. Blázquez-J. Alvar (eds.), La romanización en Occidente, Madrid, 15-43.

Le Roux, 1995: P. Le Roux, Romains d'Espagne, Paris.

Leveau et alii, 1993: Ph. Leveau, P. Sillières, J. P. Vallat, Campagnes de la Méditerranée Romaine, Paris.

LÓPEZ, 1989: A. LÓPEZ, Excavaciones en la villa romana del Roser de Calella (El Maresme), campañas de 1981 y 1982, Empúries, 47, 162-209.

LÓPEZ, 1991: A. LóPEZ, J. Fierro, Un conjunt ceràmic de l'època Baix-republicana trobat a l'esta- 
bliment ibèric de Darró, Vilanova i la Geltrú, Miscel.lània Penedesenca, XV, 139-182.

LÓPEZ, 1992: A. LÓPEZ, Les primeres estratigrafies a la vil.la romana dels Atmetllers, Tribuna d'Arqueologia 1990-91, 73-92.

LóPEZ et alii, 1985: A. LóPEZ, M. Zucchitello, X. Fierro, Resultats de la primera campanya d'excavacions a la vil.la romana del Mas Carbotí, Informació Arqueológica, 44, 38-43.

LÓPEZ et alii, 1987: A. LÓPEZ, R. BATISTA, M. ZuCCHITELLO, La producción vitivinícola de la Tarraconense, algunos ejemplos sintomáticos, El ví a l'Antiguitat. Economia, producció i comerç al Mediterrani Occidental, Badalona, 319326.

López et alii, 1992: A. López, A. CaiXal, X. Fierro, A. Castellano, La primera Vilanova, I.E.P. 67 , Vilanova.

LóPez Pérez, 1994: G. LóPez PÉRez, La villa romana de la Salut de Sabadell y su complejo termal, Espacio, Tiempo y Forma, Serie I (Prehistoria y Arqueología), 7, 357-369.

Macias-Remolì, 1993: J. Ma Macías, J. A. RemolÀ, Anàlisi de l'hàbitat d'època ibero-romana a la zona de l'Albornar (Sta. Oliva, Baix Penedès), Miscel.lània Penedesenca, XVI, 139-162.

Martínez et alii, 1988: J. Martínez, J. Folch, T. CASAS, La intervenció arqueològica al jaciment ibèric i romà de Can Feu (1987). Notes preliminars, Arraona, 3, 25-34.

MAYER-RodÀ, 1986: M. MAYeR, I. RodÀ, La romanització de Catalunya. Algunes qüestions, 6è CIAP. Puigcerdà.

Miret-Revilla, 1990: M. Miret, V. Revilla, Observacions sobre el poblament romà a la Marina del Penedès, La Romanització del Pirineu. Sè CIAP (1988), Puigcerdà, 209-214.

Miret et alii, 1988: M. Miret, J. Sanmartí, J. SanTACANA, La evolución y el cambio del modelo de poblamiento ibérico ante la romanización: un ejemplo, Los asentamientos ibéricos ante la romanización, Madrid, 79-88.

Miret et alii, 1991: Miret, Sanmartí, Santacana, From indigenous structures to the roman world: models for the occupation of central coastal Catalunya, en Barker-Lloyd (eds.), Roman Landscape archaeological survey in the Mediterranean region, London, 47-53.

Miró, 1988: J. Miró, La producción de ánforas romanas en Catalunya. Un estudio sobre el comercio del vino de la Tarraconense (I a.C.-I d.C.), BAR Int. Series 473, Oxford.

Molas et alii, 1995: M. Durán, M. D. Molas, I. Mestres, J. Pujades, L'establiment Iberoromà del Camp de les Lloses (Tona), Tribuna d'Arqueologia 1993-94, 63-74.

Nolla, 1982-83: J. M. Nolla, La vil.la del Pla de l'Horta a Sarrià de Dalt, Annals I.E.G., XXVI, 111-130.

Nolla et alii, 1995: J. Casas, P. Castanyer, J. M. Nolla, J. Tremoleda, El món rural d'època romana a Catalunya. L'exemple del Nord-Est., C.I.A.G. 15, Girona.

Olesti, 1995: O. Olesti, El territori del Maresme en època republicana (s. III-I a.C.): estudi d'Arqueomorfologia $i$ Història, (Premio Iluro 1994), Mataró.

Olesti, 1996-97: O. Olesti, Els primers productors d'àmfores vinícoles al Maresme, Hispània $i$ Roma. D'August a Carlemnay, Annals de l'Institut d'Estudis Gironins, XXXVI.

Palau-Ribes, 1978: M. Palau-Ribes, El jaciment de la Plaça de les Bruixes (Molins de Rei), Memoria de Licenciatura inédita U.B.

Palet et alii, 1993: J. M. Palet, J. Pou, V. Revilla, La vil.la romana de El Vilarenc (Calafell), $\mathrm{Ho}-$ menatge al Dr. M. Tarradell, Barcelona, 723751.

Pou-Revilla, 1993: J. Pou, V. Revilla, El Vilarenc. Memòria de la campanya 1993, Memoria de excavación inédita, Servei d'Arqueologia de la Generalitat de Catalunya.

Pou-Revilla, 1996: J. Pou, V. Revilla, La villa romana de El Vilarenc: campanyes 1988-94, Tribuna d'Arqueologia 1994-95, 105-112.

Panosa, 1991: M. I. PAnosa, L'escriptura ibèrica al Nord-Est Peninsular i el seu marc socio-econòmic entre el s. IV-I a.C., Tesis Doctoral inédita U.A.B., Bellaterra. Algunos apartados han sido publicados en Limes, 2 y 3 (1992-93).

Panosa, 1993: M. I. PANosA, Nuevas inscripciones ibéricas de Cataluña, Complutum, 4, 175-222.

Plana, 1990: R. Plana, Morfologia històrica del territori del Nord-Est Català durant les èpoques pre-romana $i$ romana, Tesis Doctoral inédita U.A.B., Bellaterra.

Prevosti, 1981: M. Prevosti, Cronologia i poblament a l'area rural d'Iluro (Premi Iluro 1980), Mataró.

Prevosti, 1984: M. Prevosti, L'estudi del món rural romà. Un programa metodològic, Fonaments, 4, 161-211.

Prevosti, 1991: M. Prevosti, The establishment of the villa system in the Maresme (Catalonia) and its development in the Roman period, Arch. monographs of the British School at Rome, 2, London, 135-141.

Prevosti-Sanmartí-Santacana 1987: M. Prevosti, J. 
Sanmartí, J. Santacana, Algunes hipotèsis sobre els objectius i estratègies de la colonització romana a la costa central de Catalunya, Jornades Intern. d'Arqueologia Romana, Granollers, 85-96.

Prieto, 1995: A. Prieto, L'espace social du pouvoir en Hispanie Romaine, Pouvoir et «Imperium», Diaphora, 6, 213-226.

Py, 1990: M. Py, Mobilier céramique. Productions et importations, Lattara, 3, 329-350.

Revilla, 1995: V. Revilla, Producción cerámica, viticultura y propiedad rural en Hispania Tarraconensis, Barcelona.

RiBAS, 1983-84: M. RibAS, Un taller d'àmfores a Mataró, Pyrenae, 19, 281-286.

Richardson, 1987: J. S. RichaRdSOn, Spain and the Development of Roman Imperalism, 218-82 a.C., Cambridge.

Ruiz-Molinos, 1993: A. Ruiz, M. Molinos, Los Iberos. Análisis arqueológico de un proceso histórico, Barcelona.

SÁncheZ-BARrassetes, 1989: E. SÁnchez, E. Barrassetes, Memòria de les excavacions al jaciment de Can Rossell (c/ J. Argila), Memoria de excavación inédita, Servei d'Arqueologia de la Generalitat. Un resumen en Anuari d'intervencions arqueològiques a Catalunya, 1, Barcelona, 1993, 285.

Sanmartí et alii, 1984: J. Sanmartí, J. Santacana,
R. SERrA, El jaciment ibèric de l'Argilera i el poblament protohistòric al Baix Penedés, Quaderns de treball, 6.

Sanmartí-Santacana, 1992: J. Sanmartí, J. SantaCANA, El Poblat ibèric d'Alorda Park, Excavacions Arq. a Catalunya 11, Barcelona.

Sanmartí-Santacana-Pou, 1992: J. Sanmartí, J. Santacana, J. Pou, El poblament Ibèric a 1'àrea Cosetana, Laietania, 8, 181-206.

Serra RÀfols, 1962: J. DE C. Serra RÀfols, Estratos ibéricos debajo de villas romanas de la costa catalana, VII Congreso Nacional de Arqueología, Zaragoza, 255-260.

Solias, 1993: J. M. Solias, El curs inferior del Llobregat en època ibèrica i romana. Evolució històrica i models de poblament, Estrat, 6, 77-103.

Terré, 1987: E. Terré, La vil.la romana de «El Moro» (Torredembarra): un exemple de poblament rural al camp de Tarragona, Jornades Intern. d'Arqueologia Romana, Granollers, 217224.

Vicente et alii, 1991: Vicente, Punter, Escriche, Herce, La Caridad (Caminreal, Teruel), La casa urbana Hispanorromana, Zaragoza, 81-130.

Villanueva, 1994: M. Villanueva, Aspectos de la organización económica de las villae en Hispania, Espacio, Tiempo y Forma, serie II ( $\mathrm{H}^{\mathrm{a}}$ Antigua), 7, 105-140. 